\title{
Assessing the Impact of Underwater Clearance of Unexploded Ordnance on Harbour Porpoises (Phocoena phocoena) in the Southern North Sea
}

\author{
Alexander M. von Benda-Beckmann, ${ }^{1}$ Geert Aarts ${ }^{2,3}$ H. Özkan Sertlek, ${ }^{4,5}$ \\ Klaus Lucke, ${ }^{2,6}$ Wim C. Verboom, ${ }^{7}$ Ronald A. Kastelein, ${ }^{8}$ Darlene R. Ketten, ${ }^{9}$ \\ Rob van Bemmelen, ${ }^{2}$ Frans-Peter A. Lam, ${ }^{1}$ Roger J. Kirkwood, ${ }^{2}$ \\ and Michael A. Ainslie ${ }^{1,10}$ \\ ${ }^{1}$ TNO Acoustics and Sonar, Oude Waalsdorperweg 63, 2597 AK, The Hague, The Netherlands \\ E-mail: sander.vonbenda@tno.nl \\ ${ }^{2} I M A R E S$, Wageningen UR, Zuiderhaaks 5, 1797 SH 't, Horntje, The Netherlands \\ ${ }^{3}$ Department of Aquatic Ecology \& Water Quality Management (AEW), Wageningen University, \\ Droevendaalsesteeg 3a, Building 100, 6708 PB, Wageningen, The Netherlands \\ ${ }_{4}^{4}$ Institute of Biology Leiden, Leiden University, Sylviusweg 72, 2333 BE, Leiden, The Netherlands \\ ${ }^{5}$ Electronics Engineering Department, Gebze Institute of Technology, PO Box 141, 41400, Gebze, Turkey \\ ${ }^{6}$ Centre for Marine Science \& Technology, Curtin University, GPO Box U1987, Perth, WA 6845, Australia \\ ${ }^{7} J$ unoBioacoustics, Dorpsstraat 1-a, 1731 RA, Winkel, The Netherlands \\ ${ }^{8}$ SEAMARCO, Julianalaan 46, 3843 CC, Harderwijk, The Netherlands \\ ${ }^{9}$ Hanse Wissenschaftskollegg Institute for Advanced Studies, Neurosciences \\ and Marine Sciences, Delmenhorst, 27753 Germany \\ ${ }^{10}$ Institute of Sound and Vibration Research, University of Southampton, Highfield, Southampton SO17 1BJ, UK
}

\begin{abstract}
Large amounts of legacy unexploded ordnance (UXO) are still present in the North Sea. UXO are frequently accidentally encountered by fishermen and dredging vessels. Out of concern for human safety and to avoid damage to equipment and infrastructure from uncontrolled explosions, most reported UXO found in the Dutch Continental Shelf (DCS) are detonated in a controlled way. These underwater detonations produce high amplitude shock waves that may adversely affect marine mammals. The most abundant marine mammal in the DCS is the harbour porpoise (Phocoena phocoena), a species demonstrated to be highly sensitive to sound. Therefore, an assessment of potential impacts of underwater explosions on harbour porpoises was undertaken. Information regarding UXO cleared in the DCS provided by the Netherlands Ministry of Defence was used in a propagation model to produce sound exposure maps. These were combined with estimates of exposure levels predicted to cause hearing loss in harbour porpoises and survey-based models of harbour porpoise seasonal distribution on the DCS. It was estimated that in a 1-y period, the 88 explosions that occurred in the DCS very likely caused 1,280, and possibly up to 5,450 , permanent hearing loss events (i.e., instances of a
\end{abstract}

harbour porpoise predicted to have received sufficient sound exposure to cause permanent hearing loss). This study is the first to address the impacts of underwater explosions on the population scale of a marine mammal species. The methodology is applicable to other studies on the effects of underwater explosions on the marine environment.

Key Words: underwater explosions, harbour porpoise, Phocoena phocoena, hearing loss, marine acoustics, anthropogenic noise, Dutch Continental Shelf

\section{Introduction}

Large numbers of unexploded ordnance (UXO), such as aerial bombs, ammunition, mines, and torpedoes, mostly legacies of World War II, remain in the North Sea. UXO are frequently accidentally encountered by fishermen and dredging vessels (OSPAR Commission, 2010). There is a societal need for clearance of UXO as they pose a risk to offshore activities such as fishing, dredging, and pipe-laying. For example, in 2005, three Dutch fishermen were killed by a bomb that was caught in their net and exploded on deck (OSPAR Commission, 2010). The Royal Netherlands Navy (RNLN) is tasked with clearing UXO from the Dutch Continental Shelf (DCS) and executes on 
average approximately 120 underwater detonations per year.

Underwater detonations of explosives produce some of the highest peak sound pressures of all underwater anthropogenic sound sources. The number of underwater detonations in the North Sea, as well as their high intensity shock waves and sound levels, has raised concerns about their impact on marine life (Nützel, 2008; Ainslie et al., 2009; Camphuysen \& Siemensma, 2011; Koschinski, 2012). The high amplitude shock waves and the attendant sound wave produced by underwater detonations of UXO have the potential to cause injury or death to marine vertebrates and invertebrates (e.g., Ketten et al., 1993; Richardson et al., 1995; Lewis, 1996; Ketten, 2004, 2012; Danil \& St. Leger, 2011).

The harbour porpoise (Phocoena phocoena) is the most abundant marine mammal species in the DCS and adjacent waters. In recent years, the harbour porpoise population has undergone a redistribution across its North Sea range resulting in an increase in abundance in Dutch waters (Camphuysen, 2011), with some 10,000s of animals now present (Geelhoed et al., 2012).

Harbour porpoises have sensitive hearing, making them potentially exceptionally vulnerable to noise-induced effects from anthropogenic sound-producing activities at sea (Culik et al., 2001; Kastelein et al., 2002 , 2010, 2012a, 2012b, 2013, 2014a, 2014b, 2015a, 2015b; Ketten, 2004; Lucke et al., 2009; Tougaard et al., 2009). The main potential effects of concern of underwater explosions on an individual animal are (1) trauma (from direct or indirect blast wave effect injury) such as crushing, fracturing, hemorrhages, and rupture of body tissues caused by the blast wave, resulting in immediate or eventual mortality; (2) auditory impairment (from exposure to the acoustic wave), resulting in a temporary or permanent hearing loss such as temporary threshold shift (TTS) and permanent threshold shift (PTS); or (3) behavioural change, such as disturbance to feeding, mating, breeding, and resting. Studies of blast effects on cetaceans indicate that smaller species are at greatest risk for shock wave or blast injuries (Ketten, 2004).

Underwater sound plays an important role in the lives of harbour porpoises. They use sound actively and passively for social interaction, communication, navigation, predator avoidance, and foraging (Tyack, 2008; Clausen et al., 2010). Interference or impairment of their hearing ability as a result of underwater explosions, therefore, may directly or indirectly affect their reproduction and longevity. For instance, loss of important social bonds due to impaired communication (e.g., contact between mother and calf) or loss of prey could produce significant population-level consequences (National Research Council, 2005).

The objective of this study was to assess the potential impact of underwater explosions due to clearance activities of UXO on North Sea harbour porpoises. Sound levels were estimated for explosions in shallow water, which were then compared to risk thresholds and distributions of harbour porpoises. It was decided to focus on explosion levels high enough to cause hearing loss in harbour porpoises, which are likely to occur at lower levels than possible direct traumatic injuries. Potential behavioural responses of harbour porpoises to single explosion events were not considered in this study. A paucity of observations of wild harbour porpoise responses to explosions (single sound transients) made it impossible to address the severity of responses to single explosion events.

Since there is a lack of acoustic measurements for large explosions (charge mass much larger than $1 \mathrm{~kg}$ TNT equivalent) in shallow waters (bottom depths less than $50 \mathrm{~m}$ ) (Weston, 1960; Chapman, 1985; Soloway \& Dahl, 2014), measurements of sound produced by several large underwater explosives in shallow water environments were carried out. These measurements were used to correct deep water source models for explosions and were used in combination with a shallow water propagation model to generate maps of received sound exposure level (SEL) for the reported explosions in 2010 and 2011. Reported levels of impulsive sound that cause blast injury to harbour porpoises were reviewed (Ketten, 2004) to determine a range of onset thresholds at which explosions are expected to cause permanent hearing loss. Herein, permanent hearing loss refers to a permanent reduction (at least partial) in hearing capability resulting from the blast wave or acoustic components of the explosion.

The sound propagation maps, available risk thresholds, and aerial survey derived harbour porpoise density estimates (Geelhoed et al., 2012; Aarts et al., in prep.) were combined to obtain an estimate of the annual number of possible impact events (i.e., instances of a harbour porpoise receiving sufficient sound exposure to cause hearing loss). The estimated number of impact events were used to discuss the implications of UXO clearance for the North Sea harbour porpoise population.

\section{Methods}

Overview of Clearance Activities by the RNLN in the Southern North Sea

Since 2005, the RNLN has recorded the approximate location, type of ordnance, and date of detonation for destroyed underwater ordnance but not 
always the charge mass. Because the detonations can interfere with geoseismic monitoring, all detonations exceeding $25 \mathrm{~kg}$ (TNT eq.) were also reported to the Royal Netherlands Meteorological Institute (KNMI). These KNMI reports provided precise locations, times, and charge masses of the explosions. For this study, activities over a $2-y$ period (2010 and 2011) were investigated using the combined RNLN and KNMI datasets. These lists were merged into a final list by removing the same detonations occurring in both lists; in such cases, the information in the KNMI report was retained. In some cases, small counter-charges used to detonate the main charge were listed separately. In such cases, only the main charge mass (usually much larger) was considered.

The final list comprised 210 explosions of which 181 were within the DCS and 29 outside the DCS (a detailed list of explosions can be found in von Benda-Beckmann et al., 2015). Of the 210 explosions, 62 had an unknown charge mass. These were most likely smaller explosions (e.g., of grenades and other small ammunition) that were below the $25 \mathrm{~kg}$ (TNT eq.) that is required to be reported to the KNMI. An expert on explosives estimated the charge mass of these smaller explosives to be in the range of 5 to $20 \mathrm{~kg}$ (TNT eq.) (R. van Wees, pers. comm.); therefore, for the purpose of this study, unknown charge masses were assumed to be $10 \mathrm{~kg}$ (TNT eq.).

\section{Pressure Measurements of Large Explosions in Shallow Water}

The acoustical properties of explosives are summarised by Weston $(1960,1962)$. The main feature is a short shock wave comprising a sharpalmost instantaneous - rise in pressure followed by an exponential decay with a time constant of a few hundred microseconds. The expanding shock wave creates a large pulsating bubble with successive expansions and contractions that give rise to a series of weaker, more symmetrical bubble pulses as happens also with an airgun pulse (Weston, 1960; Cole, 1965). In shallow water, the multiple interactions of the shock and acoustic waves create a more complex pattern. Because of a lack of published measurements for explosions in shallow water (see Soloway \& Dahl, 2014), especially for a charge mass much larger than $1 \mathrm{~kg}$, a field experiment was carried out in 2010 to measure multiple detonations of aerial bombs at varying ranges up to approximately $2 \mathrm{~km}$ from the detonation site.

Measurements of underwater pulse duration (in s), sound exposure level (SEL in $\mathrm{dB}$ re $1 \mu \mathrm{Pa}^{2} \mathrm{~s}$ ), and peak overpressure (in $\mathrm{kPa}$ ) were obtained in September 2010 for the underwater explosions of seven aerial bombs (six 1,000 lb and one $500 \mathrm{lb}$ with TNT eq. charge masses of 263 and $121 \mathrm{~kg}$, respectively). These bombs were found on land and detonated on the seafloor in an area with a water depth of 26 to $28 \mathrm{~m}$ and a sandy bottom. Measurements were obtained using a hydrophone (B\&K 8105) and ICP tourmaline pressure gages (type W138A01/M038CY060), measuring at a sampling rate of $50 \mathrm{kHz}$, set at depths of $4,5,13$, 15,23 , and $25 \mathrm{~m}$, and distances between 100 and $2,000 \mathrm{~m}$ from the source.

Underwater explosions caused a series of typical pressure changes (see Figure 1). Following Madsen (2005), the pulse duration, t90, was measured as the time containing $90 \%$ (5 to $95 \%$ ) of the energy of the signal. The SEL within one tenth of a decade (decidecade) bands as well as the broadband level were measured from each explosion within the pulse duration in a frequency band of 0 to $20 \mathrm{kHz}$. The peak overpressure (or peak compressional pressure in $\mathrm{kPa}$ ) of the shock wave, defined as the maximum value of the positive overpressure (pressure minus ambient pressure, when this quantity is positive), was measured within a set time interval (herein taken to be $0.5 \mathrm{~s}$ to cover the full explosion event).

\section{Risk Thresholds for Hearing Loss for}

Harbour Porpoises Exposed to Explosions

This study focused mainly on the risk of explosions leading to permanent hearing loss as a result of direct blast injury caused by the shock wave close to the source or PTS from the acoustic wave of the blast incident farther away from the source. Permanent hearing loss estimated herein may be partial (such as acoustically derived damage to some portion of the inner ear), occurring within a specific frequency range, or total (such as severe trauma to the auditory bulla or middle or inner ear tissues), depending on which components of the auditory system are affected and how they are affected. More severe trauma was expected to occur at higher levels than those required to cause permanent hearing loss and, as such, this was considered as a lower limit.

Permanent and Temporary Threshold ShiftsMarine mammals exposed to intense underwater sounds may suffer hearing loss, resulting in hearing threshold shifts that may be temporary (TTS) or permanent (PTS). The extent of the hearing threshold shift and the frequency range affected may depend on the sound level, spectral content, temporal pattern, and exposure duration. TTS is defined as a threshold shift that recovers to normal sensitivity. The course and time of recovery depend on several factors: the individual's recovery ability, the sound to which an animal was exposed, and the amount of shift that incurred (Kastelein et al., 2012b, 2014b, 2015a; Finneran 

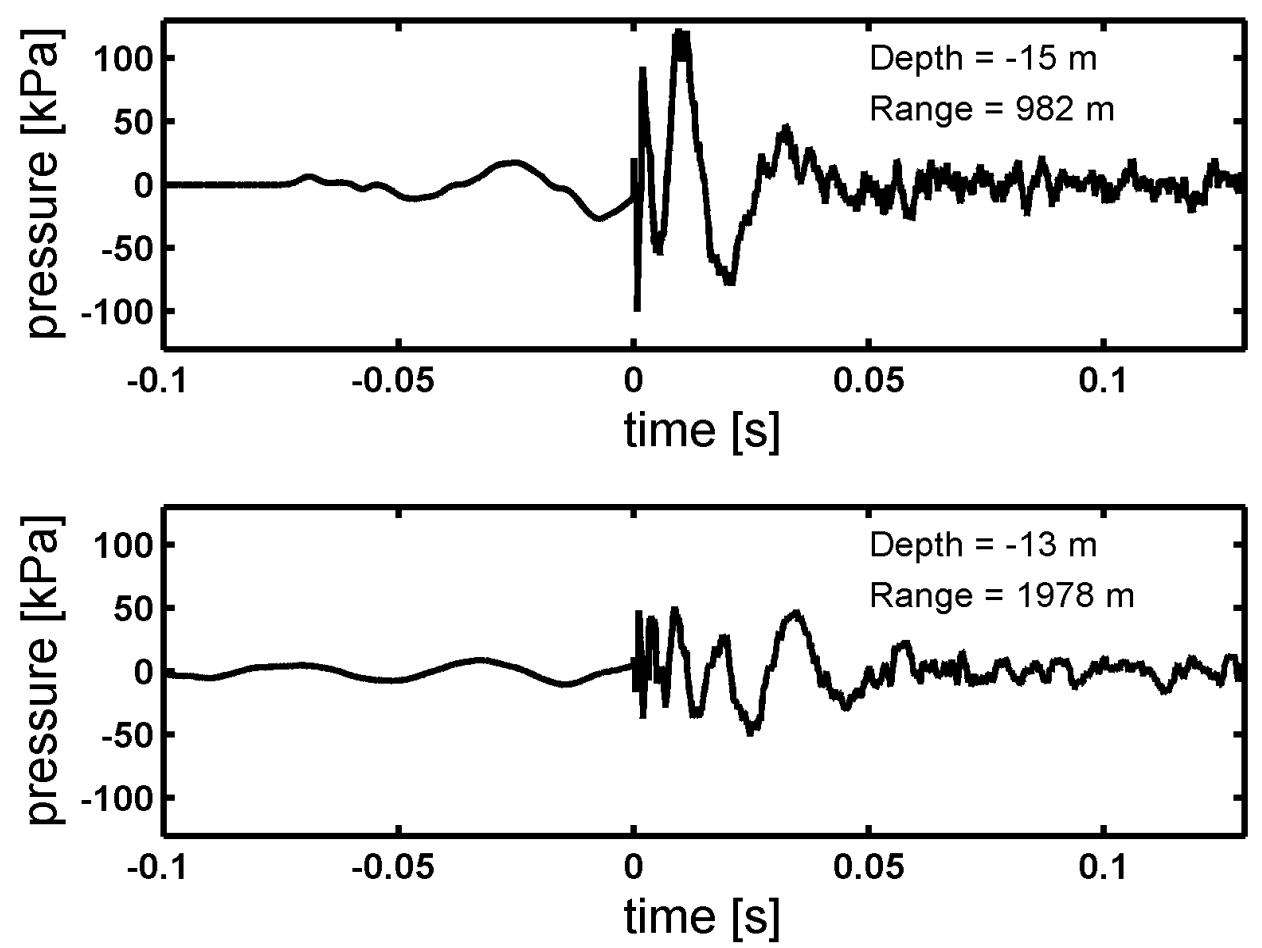

Figure 1. Examples of recorded sound pressure time-series of a detonation of a 263-kg TNT equivalent aerial bomb (measured at a sampling frequency of $50 \mathrm{kHz}$ ), recorded at a depth of $15 \mathrm{~m}$ at a distance of $982 \mathrm{~m}$ (upper) and at 13-m depth at a distance of 1,978 $\mathrm{m}$ (lower) from the explosion site. An early arrival of the ground shock wave can be observed, followed by the water-borne shock wave (at time $=0 \mathrm{~s}$ ), and reflections and bubble oscillations.

\& Schlundt, 2013). TTS onset defined herein is consistent with the criteria used in most studies on marine mammals - that is, as a TTS of $6 \mathrm{~dB}$ or greater measured shortly (1 to $4 \mathrm{~min}$ ) after cessation of the exposure, following Southall et al. (2007).

Different TTS onset SEL thresholds have been measured in harbour porpoises for a variety of pulse types (Lucke et al., 2009; Kastelein et al., 2012b, 2014b, 2015a, 2015b). Lucke et al. (2009) determined a masked TTS-onset SEL level for a harbour porpoise subjected to single airgun transients, measuring auditory evoked potentials. As the sound stimuli of Lucke et al. resembled explosion sound better than other TTS studies currently available (Kastelein et al., 2012b, 2014b, 2015a, 2015b; Tougaard et al., 2015), our estimates for SEL thresholds for TTS and PTS were based on that study.

There is currently no experimental data available for predicting PTS-onset levels in marine mammals. Observations for humans show that a TTS of 40 to $50 \mathrm{~dB}$ results in a significant risk of PTS (Kryter et al., 1966; Kryter, 1994). Southall et al. (2007) used reported TTS onset measurements for marine mammals to estimate the SEL required for a $40 \mathrm{~dB}$ TTS based on the TTS growth curve for land mammals, which has a $2.3 \mathrm{~dB}$ increase in TTS per $1 \mathrm{~dB}$ increase in SEL (i.e., the TTS growth rate is $2.3 \mathrm{~dB} / \mathrm{dB}$ ). Based on this, PTS was predicted to occur for SEL values $15 \mathrm{~dB}$ above SEL, causing TTS onset (Southall et al., 2007). Recent measurements for continuous noise exposure and sonar sound suggest that the growth rates may well exceed $2.3 \mathrm{~dB} / \mathrm{dB}$ in some cases (Kastelein et al., 2013, $2014 \mathrm{~b})$. Given the lack of data on growth rates in harbour porpoises for impulsive sounds, let alone sound from explosions, the approach for extrapolating the TTS growth that is outlined by Southall et al. (2007) was used.

To account for the frequency selective sensitivity of the mammalian hearing system in sound exposure calculations, frequency-selective weighting functions are often used (Fletcher \& Munson, 1933; Suzuki \& Takeshima, 2004; Southall et al., 2007). Several weighting curves for harbour porpoises have been proposed in the literature (Verboom \& Kastelein, 2005; Southall et al., 2007; Finneran \& Jenkins, 2012; Wensveen et al., 2014; Tougaard et al., 2015). No frequency weighting study has been conducted for an explosive sound source. Because air guns are an impulsive and low frequency source, and are fairly representative of 
an explosion sound at larger distances in shallow water, the data from an airgun study (Lucke et al., 2009) were used to define TTS onset. Therefore, no frequency weighting was applied to the SEL when estimating the risk of TTS and PTS for explosions.

Lucke et al. (2009) concluded that the predefined TTS criterion (measured at $4 \mathrm{kHz}$ ) was exceeded at received SELs greater than $164 \mathrm{~dB}$ re $1 \mu \mathrm{Pa}^{2} \mathrm{~s}$. Based on this, it, therefore, was assumed that TTS onset was very likely to occur for harbour porpoises exposed to explosion sounds at an (unweighted) SEL of $164 \mathrm{~dB}$ re $1 \mu \mathrm{Pa}^{2} \mathrm{~s}$. Following Southall et al. (2007), PTS onset was then estimated by adding $15 \mathrm{~dB}$ to the TTS onset SEL. Given the uncertainties involved in this extrapolation, this threshold should be considered as a lower limit below which PTS is considered unlikely. The resulting lower limit for onset of PTS occurred at an unweighted SEL greater than $179 \mathrm{~dB}$ re $1 \mu \mathrm{Pa}^{2} \mathrm{~s}$. At higher SELs, the risk of PTS was considered to become increasingly likely. To denote a threshold where the onset of PTS was very likely to occur, the following section considers the observations of ear trauma observed in harbour porpoises exposed to underwater explosions.

Primary Blast Injury - A study on primary blast injury in marine mammals caused by shock waves was reported by Ketten (2004). In that study, fresh odontocete cadavers (including harbour porpoises) were exposed to explosions from varying charge masses in a controlled environment. In some cases, the animals were tested within $24 \mathrm{~h}$ postmortem after chilling. In others, they were frozen within $4 \mathrm{~h}$ postmortem and prepped by thawing under controlled conditions (chiller and water bath). In all test specimens, the cadaver was scanned on receipt when fresh and rescanned just prior to testing to ensure that the lungs, brain, airways, and other major organs had tissue appearances consistent with normal anatomy and that there were no significant changes from their fresh condition. The specimens were then implanted with pressure gages for recording internal received PSI and again scanned to document the position of the gages. The necropsy and measurement of the blast effects were performed by a team consisting of experts on marine mammal physiology as well as experts on explosion-induced trauma. Trauma found included mild to severe and likely lethal injuries, particularly haemorrhages, as well as lung, esophageal, liver, brain, and ear injuries. At peak blast, overpressures exceeding $172 \mathrm{kPa}$ (25 psi) ear trauma were always observed, which was consistent with the ear being the most sensitive organ for blast-related trauma. No effects were observed for peak overpressures below 69 to $83 \mathrm{kPa}$ (10 to $12 \mathrm{psi})$.
Blast trauma to the harbour porpoise's middle and inner ear would likely result in a permanent, acute hearing loss, which could be broad spectrum such as in the case of middle ear ossicular chain disarticulation (a probable $36 \mathrm{~dB}$ loss overall due to the dysfunction of the middle ear bones; Schuknecht, 1993) or elevated thresholds in only some frequencies, depending upon the received acoustics impacting the inner ear. Observations of ear trauma and related peak overpressures, therefore, could serve as a proxy for moderate to severe permanent hearing loss.

Dose-Response Relationship for Hearing Loss-To delimit the range of SEL values at which onset of permanent hearing loss-either noise-induced PTS or ear trauma caused by the blast wave-could occur, levels at which ear trauma resulting from primary blast injury was observed were considered. Peak overpressure was used by Ketten (2004) to predict the occurrence of primary blast injury. Here, instead, the peak overpressure was empirically related to SEL for measured explosion sounds in shallow water due to the difficulties of predicting peak overpressure in shallow water. From those measured data, an effective SEL that corresponded to peak overpressures resulting in ear trauma was estimated. A corresponding upper limit for the onset of PTS was estimated using the observations by Ketten (2004) in combination with measured SEL and peak overpressure for shallow water explosions (see Appendix A for full details). The expectation was that levels just below those required to cause minimal detectable ear trauma were very likely to be sufficient to cause PTS (i.e., the borderline between detectable blast injury and acoustic effects). Table 1 summarizes the SEL thresholds adopted in this study for the risk of temporary and permanent hearing loss for harbour porpoises, which were considered appropriate for harbour porpoises exposed to underwater explosions in shallow waters (less than 50-m depth).

\section{Modelling of Sound Exposure Levels of} Explosions at Large Distances in Shallow Water Although the measurements of the charges presented in the previous section are representative of typical UXO found in the North Sea, the inventories of the 2010 and 2011 detonations showed a wide range of explosive charge masses found in a range of water depths. The water depth affects the sound propagation characteristics, particularly of low frequency sound. A source model was required, therefore, to estimate the effect of underwater explosions for which there were no empirical data. The model used in this study for predicting the impact area for harbour porpoises consisted of two parts: (1) a source model for 
Table 1. Thresholds related to temporary and permanent hearing loss caused by a single underwater explosion in shallow water $(<50-\mathrm{m}$ depth). Permanent hearing loss can be either noise-induced permanent threshold shift (PTS) or be due to ear trauma caused by the blast wave. The right column indicates the best estimate for unweighted broadband (measured in 0 to $20 \mathrm{kHz}$ ) SEL risk thresholds for "permanent hearing loss" induced by explosions. To indicate the chance of an effect to occur, the following terminology was adopted: "very likely" indicates a probability exceeding 95\%, and "unlikely" indicates a probability of less than 5\%. "Increasingly likely" is then anything between 5 and $95 \%$ probability. Arrows = ranges of SEL thresholds for onset of permanent hearing loss that are estimated to occur (see text and Appendix A for more details).

\begin{tabular}{|c|c|c|c|c|}
\hline $\begin{array}{c}\text { SEL } \\
\text { (unweighted) } \\
\left(\mathrm{dB} \text { re } 1 \mu \mathrm{Pa}^{2} \mathrm{~s}\right)\end{array}$ & $\begin{array}{c}\text { Noise- } \\
\text { induced TTS }\end{array}$ & $\begin{array}{l}\text { Noise- } \\
\text { induced } \\
\text { PTS }\end{array}$ & $\begin{array}{c}\text { Blast wave- } \\
\text { induced ear } \\
\text { trauma }\end{array}$ & $\begin{array}{l}\text { Permanent } \\
\text { hearing loss }\end{array}$ \\
\hline$>203$ & \multirow{4}{*}{ Very likely } & \multirow{2}{*}{ Very likely* } & Very likely & \multirow{2}{*}{ Very likely } \\
\hline $190-203$ & & & $\begin{array}{c}\text { Increasingly } \\
\text { likely }\end{array}$ & \\
\hline $179-190$ & & $\begin{array}{c}\text { Increasingly } \\
\text { likely }\end{array}$ & \multirow{3}{*}{ Unlikely } & $\begin{array}{c}\text { Increasingly } \\
\text { likely }\end{array}$ \\
\hline $164-179$ & & \multirow{2}{*}{ Unlikely } & & \multirow{2}{*}{ Unlikely } \\
\hline$<164$ & Unlikely & & & \\
\hline
\end{tabular}

*Based on expert judgement

underwater explosions and (2) a sound propagation model for shallow water environments.

The source model was based on the empirical deep-water formula for explosion energy as a function of distance by Weston (1960). That model contained the energy contribution of both the shock wave as well as the first two bubble oscillations. From the Weston empirical relation, a linear source model was estimated by considering the energy spectrum at a distance of 5,000 charge radii beyond which the sound wave is assumed to become linear (Ainslie, 2010) and back-computing this spectrum to a source energy level using spherical spreading. Thus, a spectral energy level was obtained for each decidecade frequency bin in a range from $10 \mathrm{~Hz}$ to $20 \mathrm{kHz}$.

The propagation model SOPRANO, proposed by Sertlek \& Ainslie (2014) and Sertlek et al. (in prep.), was used for calculating propagation loss in shallow water environments. SOPRANO is a hybrid model based on normal mode and flux theories. It is a fast analytical model which can estimate incoherent propagation loss with an accuracy similar to that of other propagation models (Sertlek et al., in prep.). The SEL was then obtained by subtracting the propagation loss from the source energy level.

This model enabled the generation of sound maps (i.e., geographical distributions of SEL for each decidecade band) with high resolution and broad range frequencies, including range-dependent bathymetry (with adiabatic approximation) and sediment type effects. For bathymetric data, the EMODNET database was used, which has a grid size of $0.125 \times 0.125 \mathrm{~min}$ (www.emodnethydrography.eu). Information for describing the geoacoustical properties of the seabed was obtained from the DINO database (https://www.dinoloket. $\mathrm{nl}$ ). Propagation loss was calculated with $25-\mathrm{m}$ resolution, and the computed SEL was then mapped onto a sound map with resolution of $1 \mathrm{~km}$ $\times 1 \mathrm{~km}$ (Figure 2). Sea surface was assumed to be flat, and effects of non-constant sound speed profiles were neglected.

To relate effects of explosions to the risk of hearing loss, an estimate for the peak overpressure was 
required. For deep water explosions, peak overpressure can be estimated using empirical models (Weston, 1960; Chapman, 1985). However, in shallow water, estimation of peak sound pressure is challenging because the estimate is very sensitive to bandwidth and geometry (which is poorly known). Uncertainties in geometry lead to small phase uncertainties in arrivals of different sound paths, which can have a large effect on the predicted peak pressure. The estimate of peak sound pressure, therefore, would require a sensitivity study on top of the existing computation load for a single time series. As this was not possible here, peak overpressures for which trauma from explosions were observed in harbour porpoises were related instead to effective shallow water SEL thresholds. These were more easily calculated and robust to environmental uncertainties. The empirical relationship between the measured peak overpressure and SEL is described in Appendix A.

\section{Harbour Porpoise Density Estimates}

Line transect surveys were carried out in the Dutch section of the North Sea during four seasons in 2010 and 2011 (i.e., in March, July, and October/November 2010, and in March 2011; Geelhoed et al., 2012; Scheidat et al., 2012), providing a large temporal overlap with the occurrence of explosions. In order to estimate absolute abundance, one needs to correct for nondetectability (e.g., Hiby \& Lovell, 1998). To do so, the one-sided effective strip width (taking the detection probability or $\mathrm{g}[0]$ values into account) was calculated and defined as $76.5 \mathrm{~m}$ for good sighting conditions and $27 \mathrm{~m}$ for moderate sighting conditions (Scheidat et al., 2005, 2008; Gilles et al., 2009). Next, for each grid cell $(10 \mathrm{~km} \times$ $10 \mathrm{~km}$ ), the number of harbour porpoise sightings and the effective surveyed area were calculated. A Bayesian spatial model was fitted to the data wherein the number of sightings in each grid cell was treated as a Negative Binomial distributed count, and the log of the area surveyed was treated as an offset. Spatial variability in sighting rate was modelled as a latent Gaussian random field using a two-dimensional autoregressive correlation function of order-1 (Rue et al., 2009). The final seasonal absolute harbour porpoise density estimates (illustrated in Figure 3) were overlaid with the generated soundmaps. The number of affected animals receiving an SEL as defined by the risk thresholds was then estimated by summing the number of predicted animals for each grid cell within a contour on the sound exposure map (for more detail, see Aarts et al., in prep.). This resulted in an estimate of the number of harbour porpoises affected by each explosion.
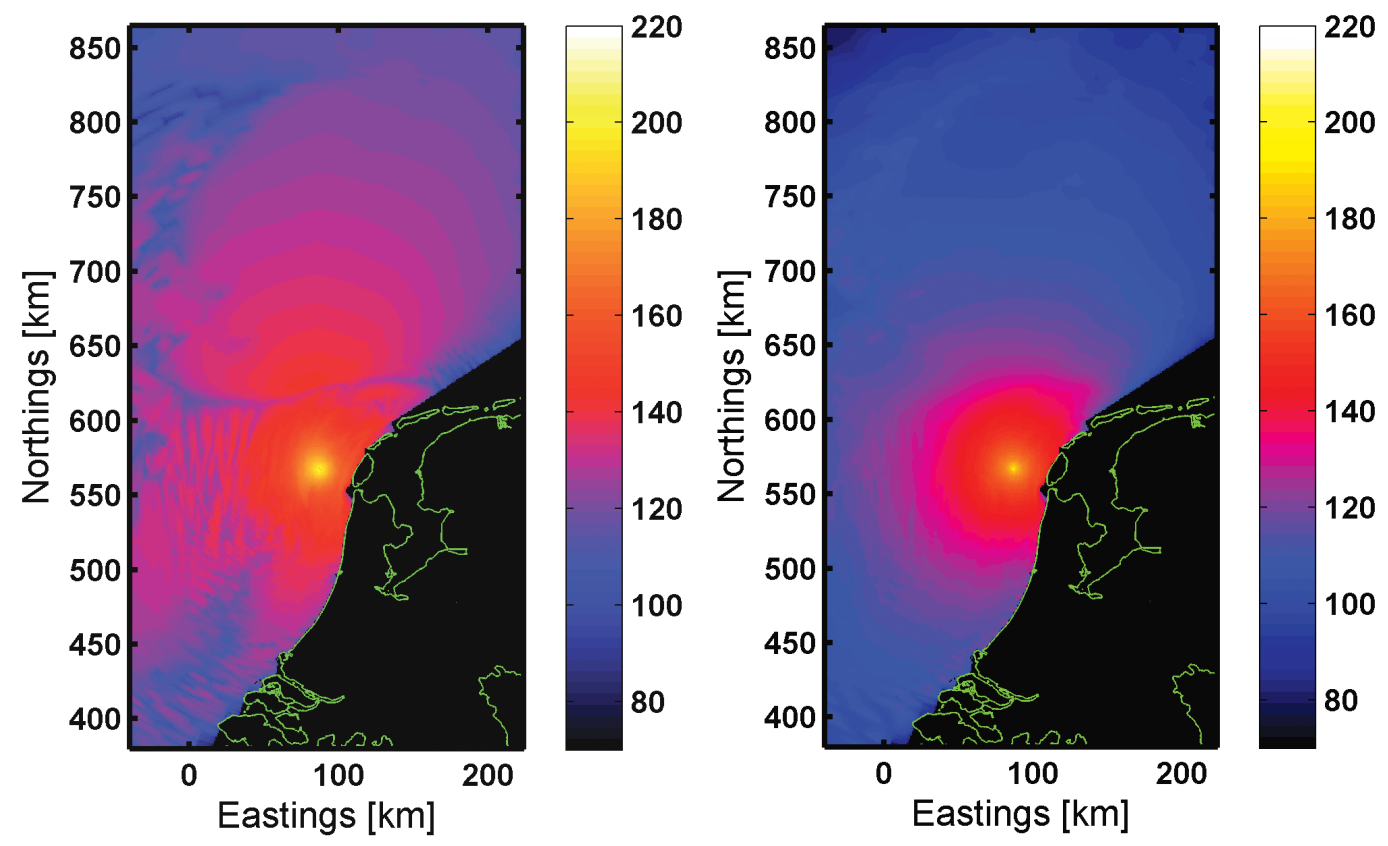

Figure 2. Examples of unweighted broadband SEL maps for a single explosion (263-kg TNT eq. charge mass) calculated for different receiver depths (at $1 \mathrm{~m}$ above the sea floor, left, and $1 \mathrm{~m}$ from the sea surface, right) computed with the model described in Sertlek \& Ainslie (2014) and Sertlek et al. (in prep.). The water depth at the detonation site is approximately $28 \mathrm{~m}$. 


\section{Mar 2011}

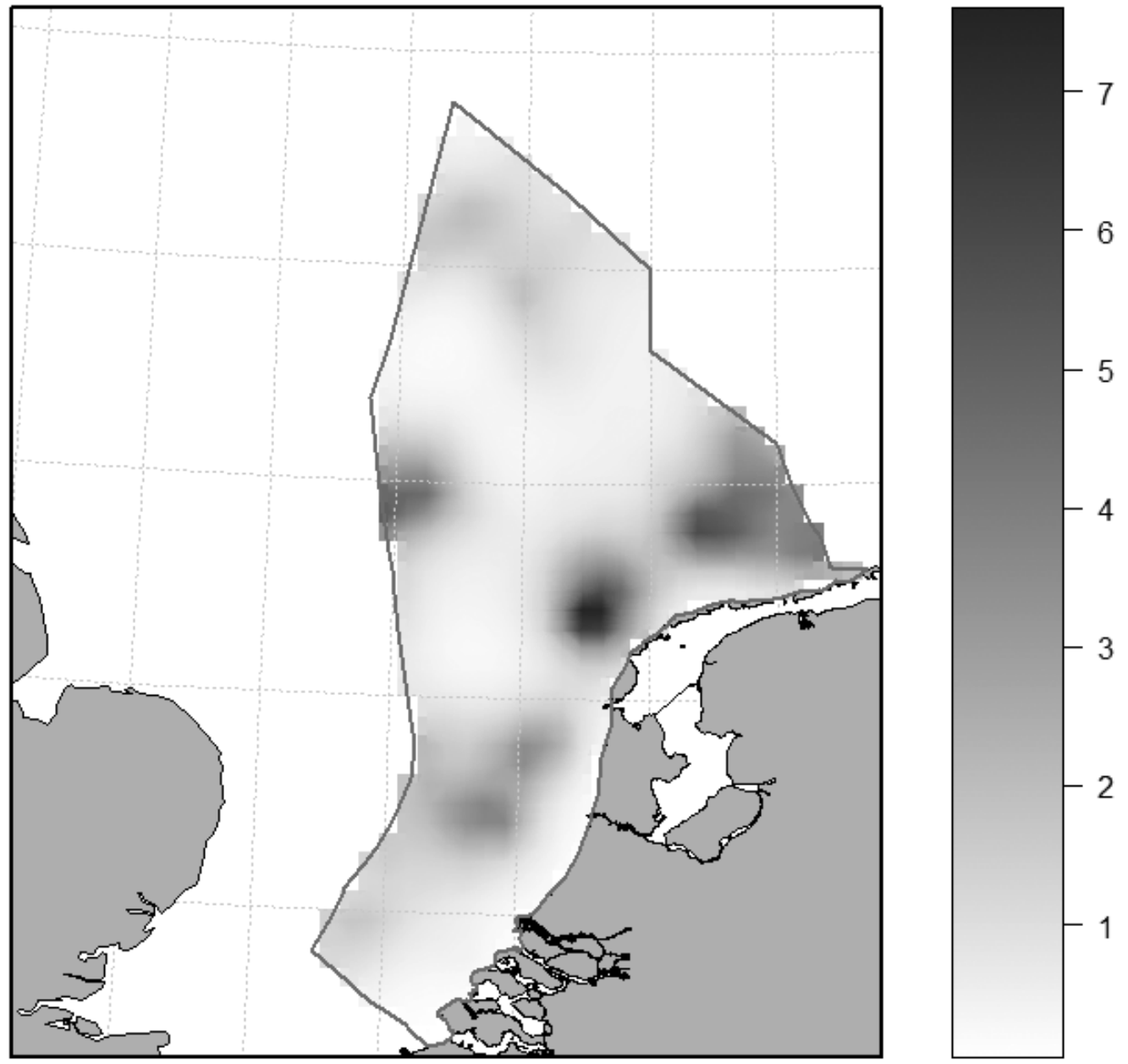

Figure 3. Example of the model-based estimates of harbour porpoise density (grey scale: number of harbour porpoises/ $\mathrm{km}^{2}$ ) within the Dutch Continental Shelf (DCS; polygon) for March 2011 based on the aerial survey performed in that month.

\section{Results}

Overview of Explosion Activities by the RNLN in the Southern North Sea

In 2010 and 2011, detonations were located predominantly in the southern DCS (Figure 4). Reported charge masses range from 10 to $1,000 \mathrm{~kg}$, with most at 125 to $250 \mathrm{~kg}$ (Figure 4). Most detonations occurred in water depths between 20 and $30 \mathrm{~m}$.

There was a distinct seasonal pattern to the explosions, with a peak in March and smaller peaks in August and November (Figure 5). The March peak coincided with a peak of fishing activity and, thus, an increase in encounter rate of UXO (OSPAR Commission, 2010).

\section{Measured SEL and Peak Overpressure of Explosions in Shallow Water}

In the measured explosions, large differences in received levels were noticeable. They were attributed to super-positioning of direct and surface reflected paths (Figure 6). SELs were on average lower near the surface than near the bottom or in the middle of the water column. This suggested that the depth where the harbour porpoise was most likely to be located needed to be considered when discussing the impact of the sound. 

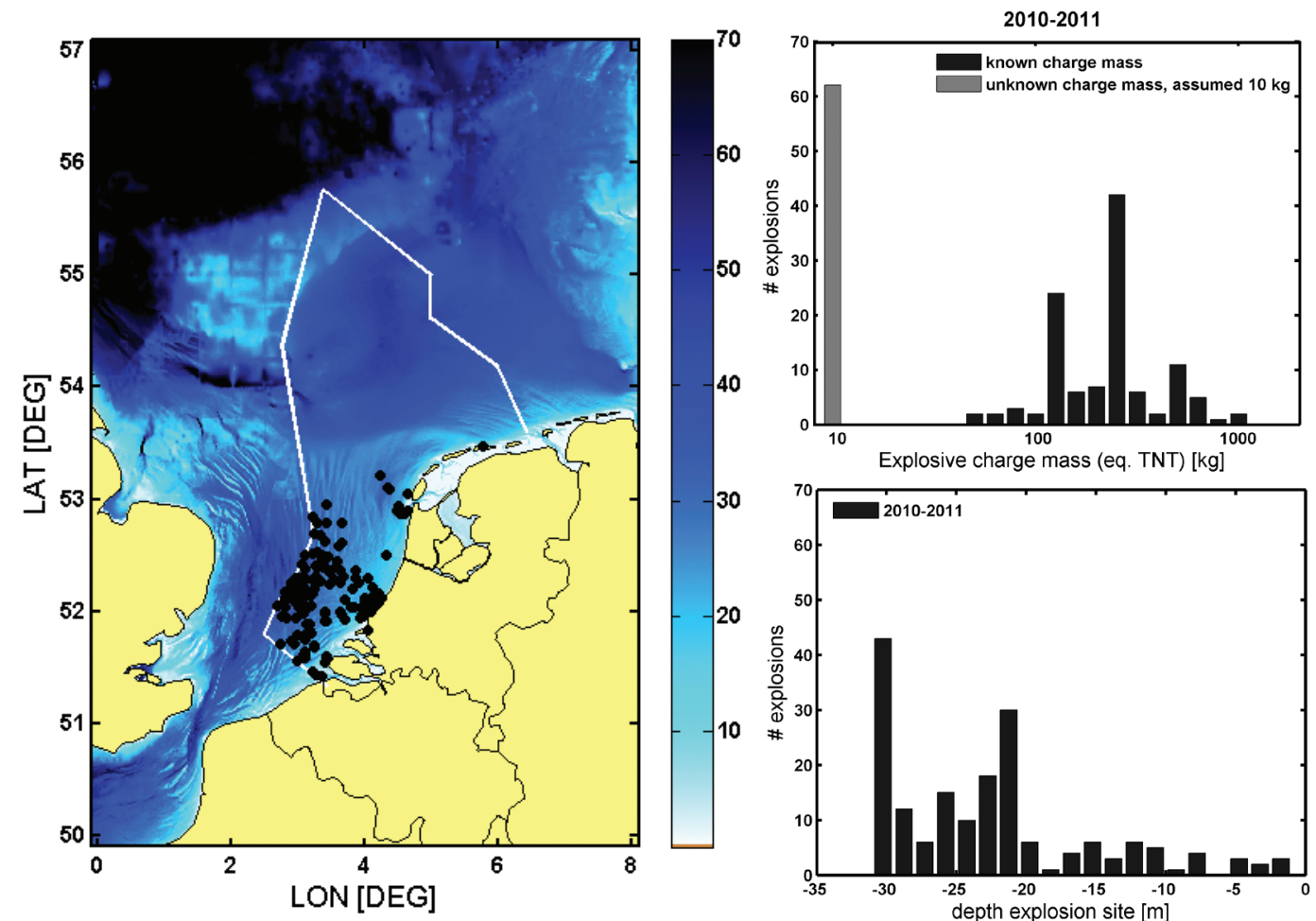

Figure 4. Geographical distribution of detonation events for the years 2010 and 2011 (left). Distribution of charge mass (TNT equivalent) (top right) and depth (bottom right) at the charge detonation site for the years 2010 and 2011. The 62 explosions for which charge masses were not available are indicated by the grey bar in the left plot. A charge mass of 10-kg TNT-eq. was assumed for these for the purpose of this study (see text for details).

\section{Comparison of Measured and Modelled Sound Levels of Explosions in Shallow Water}

Measured explosions were run through the propagation model to test its efficacy (Figure 7). The model was in agreement with the data at frequencies containing the peak energy in the spectrum between the cut-off frequency of $\sim 20$ and $100 \mathrm{~Hz}$ but systematically overestimated the measured SEL at frequencies above $100 \mathrm{~Hz}$ (Figure 7, right panel).

The systematic overestimate of SEL by the model (likely causes are interpreted in the "Discussion" section) resulted in an overestimation of $8.1 \mathrm{~dB}$ (Standard Deviation $[\mathrm{SD}]=3.6 \mathrm{~dB}$ ) of the broadband SEL. Such an overestimate would lead to a systematic overestimation of the impact ranges and, therefore, required a correction factor. For this, the power mean over each decidecade band was subtracted from the modelled SEL. After application of the correction factor, the modelled broadband SEL agreed within $0.1 \mathrm{~dB}$ $(\mathrm{SD}=3.7 \mathrm{~dB})$ from the measured broadband SEL (see Figure 6) and was used to estimate impact distances and number of affected animals.
Effect Distances for Shallow Water Detonations Based on Field Measurements

The largest distance at which the peak overpressure corresponded to risk of observed ear trauma was at approximately $500 \mathrm{~m}$ (Figure 8). Between

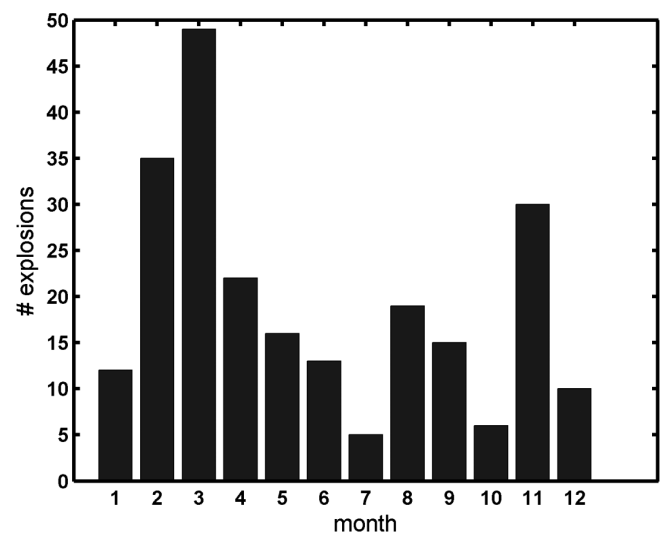

Figure 5. Number of explosion events per month in the North Sea for the years 2010 and 2011 based on the information provided by the Netherlands Ministry of Defence 

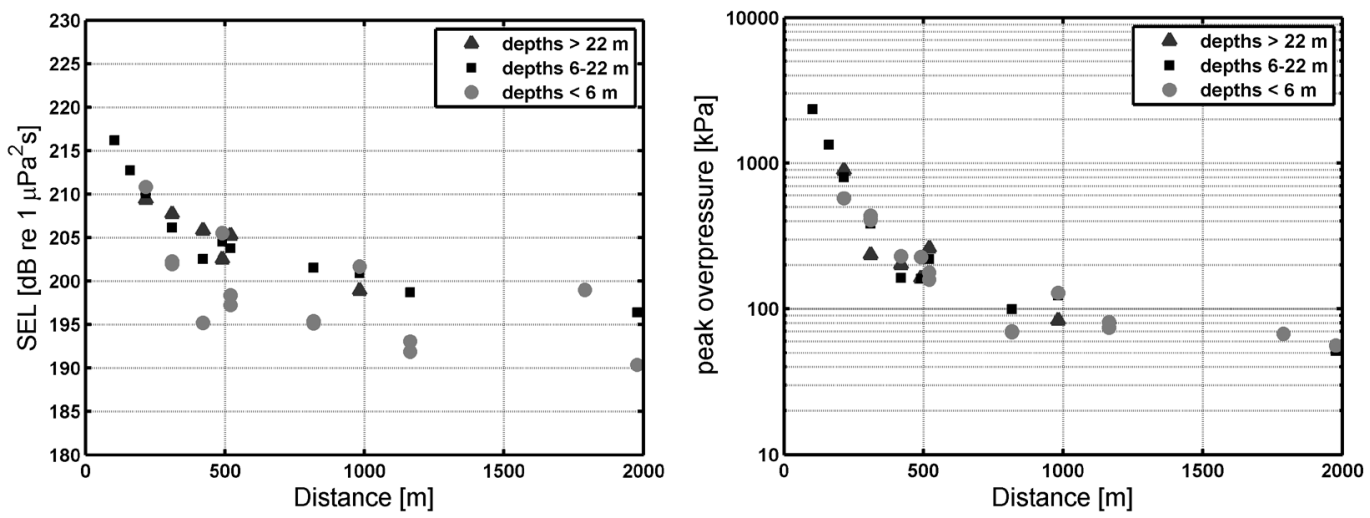

Figure 6. The 263-kg charge mass detonations measured in 2010: shown are SEL ( $\mathrm{dB}$ re $1 \mu \mathrm{Pa}^{2} \mathrm{~s}$ ) (left), peak overpressure $(\mathrm{kPa})$ (right) measured in a frequency band of $1 \mathrm{~Hz}$ to $20 \mathrm{kHz}$, at various distances from the detonation site, with recorders at varying depths (near surface $=$ circles, midwater $=$ squares, near bottom $=$ triangles). SEL values for measurements close to the surface are lower due to pressure release of sound near the surface.
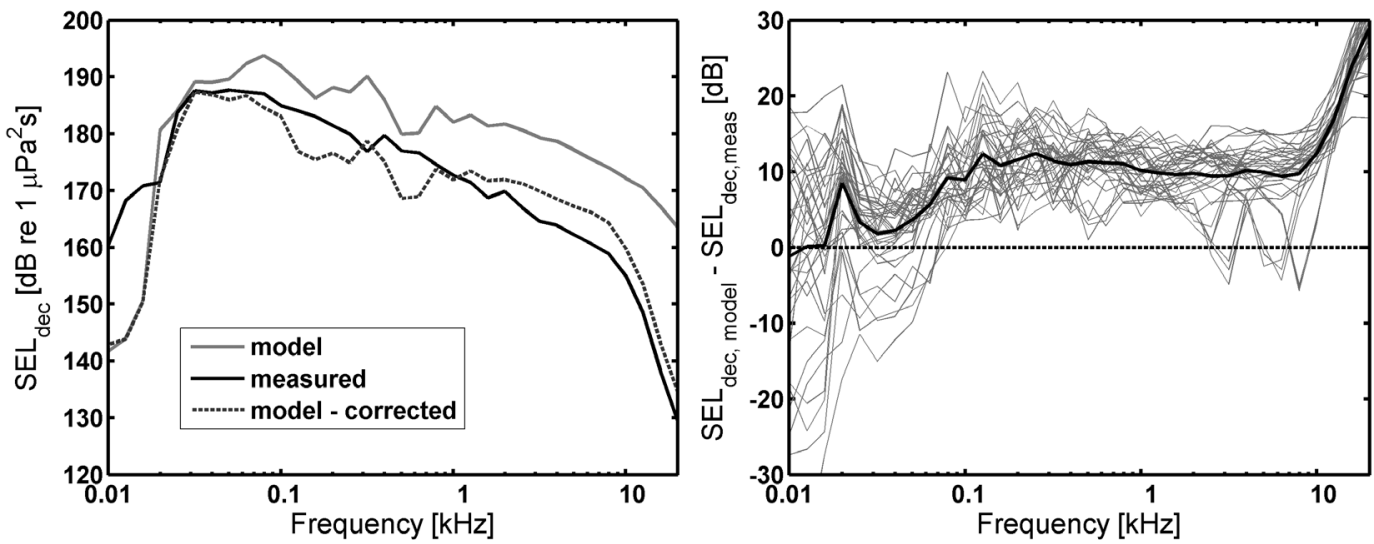

Figure 7. Left: Comparison of decidecade band SEL levels as a function of frequency for a midwater measurement at $\sim 2-\mathrm{km}$ distance (black) from an explosion, with model predictions (uncorrected: grey; corrected: dashed grey). Right: Comparison of all decidecade band SEL levels difference between model and measurements (grey lines), showing that the model tends to systematically overpredict the measured SEL, particularly at higher frequencies. The black line indicates the power mean used as the empirical correction factor to the source level used to correct for the overestimation of the model.

1,200 and $1,800 \mathrm{~m}$, the peak overpressures fell below the limit at which no ear trauma occurred. The minimum SEL measured within $2 \mathrm{~km}$ was $191 \mathrm{~dB}$ re $1 \mu \mathrm{Pa}^{2} \mathrm{~s}$, which exceeded by $1 \mathrm{~dB}$ the SEL-based risk threshold above which PTS was considered very likely (190 dB re $\left.1 \mu \mathrm{Pa}^{2} \mathrm{~s}\right)$, and exceeded by $12 \mathrm{~dB}$, the lower limit of PTS onset (179 $\mathrm{dB}$ re $\left.1 \mu \mathrm{Pa}^{2} \mathrm{~s}\right)$.

\section{Modelled Effect Distances for Harbour Porpoises} Exposed to Explosions in 2010 and 2011

Model predictions of effect distances as a function of SEL threshold were made for all explosion events occurring in the DCS in the years 2010 and 2011 (Figure 9). Effect distances for the lower limit of PTS (179 dB re $\left.1 \mu \mathrm{Pa}^{2} \mathrm{~s}\right)$ varied between hundreds of meters and $15 \mathrm{~km}$, which were higher than the empirical relationship by Weston (1960) for deep water environments. There was a trend of increasing effect distances with increased charge mass, with substantial scatter due to variations in water depth in which explosives were detonated. This indicated that the water depth in which the explosion occurs has a significant influence on the effect range for a given charge mass (Figure 10).

The density of harbour porpoises in the DCS in 2010 was dependent on season, varying between 1.34 animals $/ \mathrm{km}^{2}$ in early spring to 0.60 animals/ $\mathrm{km}^{2}$ in summer (these model-based values are similar to the values reported by Geelhoed et al., 2012, and Scheidat et al., 2012, based on traditional distance analysis). Thus, a fixed impact 


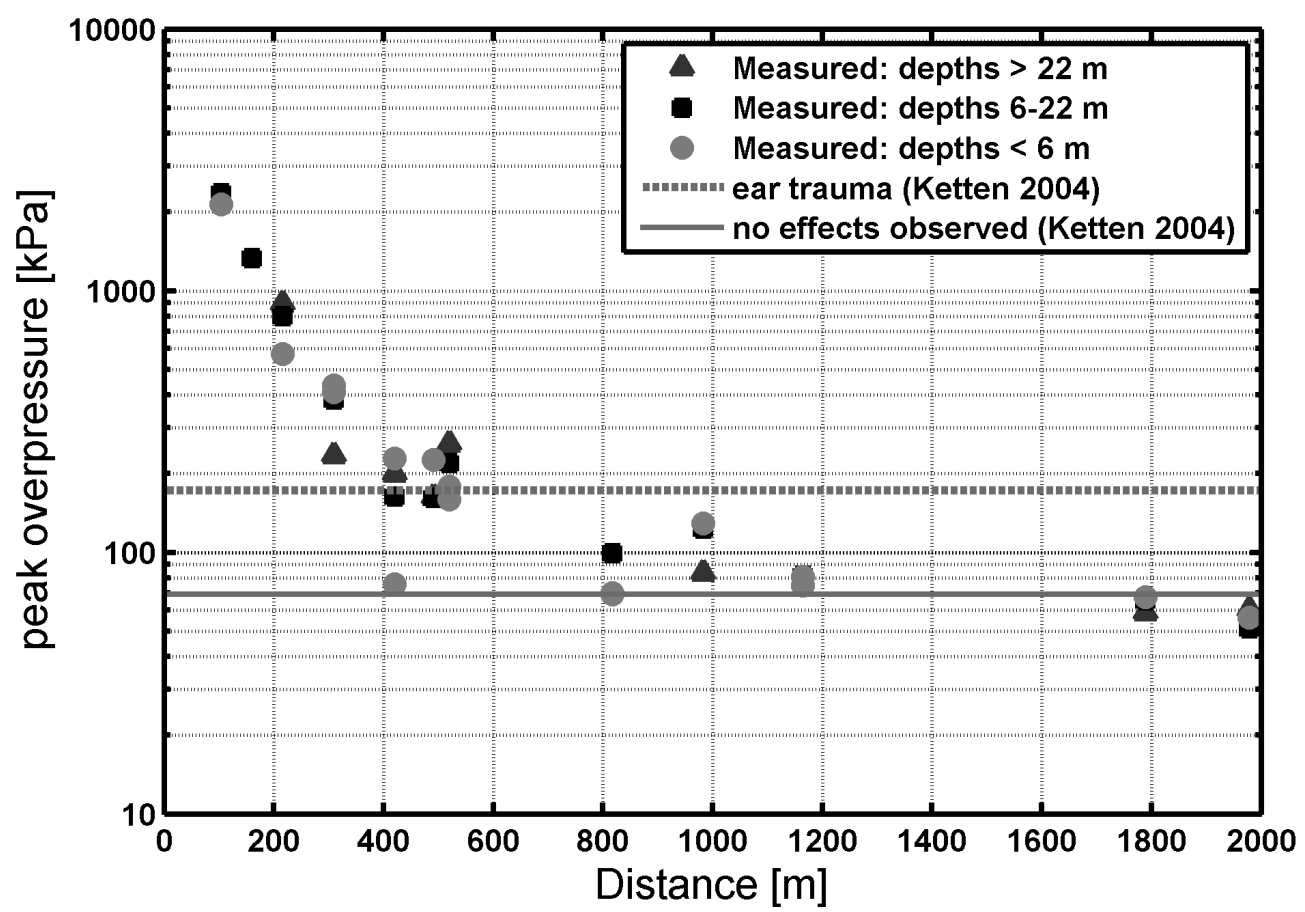

Figure 8. Effect of distances based on measured peak overpressure for a charge mass of $263 \mathrm{~kg}$ in water depth of $26 \mathrm{~m}$. Superimposed in grey are risk thresholds for blast injury from Ketten (2004).

distance would affect a different number of animals depending on the season of the event. Herein, explosions occurring in the DCS between March 2010 and March 2011 were considered (88 in total), providing a maximal temporal overlap with the aerial line-transect surveys in the DCS. By comparing modeled effect areas to measured harbour porpoise densities, the mean number of affected animals and the total number of impact events as a function of SEL threshold per explosion were estimated (Figure 11; Table 2).

Harbour porpoises were likely to receive lower SEL when near the surface than when at depth (see Figure 6). To account for this in the exposure determinations, it was assumed that harbour porpoises spent $50 \%$ of their time near the surface and 50\% near the bottom (Table 2). This assumption was based on published data for normal harbour porpoise behaviour (Westgate et al., 1995; Akamatsu et al., 2007). The average number of animals affected by each underwater explosion was then estimated by taking the mean of the number of animals exposed at $1 \mathrm{~m}$ below the surface and $1 \mathrm{~m}$ above the bottom.

A typical underwater explosion was estimated to lead to PTS in multiple individuals, with mean overall explosions ranging from 8 to
51 individuals, depending on the chosen SEL threshold level, and TTS in several hundreds of individuals (Figure 11). Although the impact area and corresponding number of harbour porpoises increased as a function of charge weight, the relationship was weakened by spatial and seasonal variability in harbour porpoise density and location of the explosion relative to topography (i.e., shallower regions more strongly attenuate sound).

Between March 2010 and March 2011 (the period with temporal overlap between harbour porpoise surveys and explosions), a total of 88 UXO were detonated by the RNLN in the DCS. These would have resulted in a total of approximately 5,450 impact events (i.e., instances in which the SEL at a harbour porpoise exceeded the estimated risk threshold) for the lower limit for permanent hearing loss and more than 28,000 TTS-onset impact events (Table 2). This was possibly an overestimation of the number of individual animals affected since some may have been affected on several occasions. The frequencies of multiple exposures depended on how individual animals move, but the probability of multiple exposures for high SEL thresholds that lead to PTS was small (Aarts et al., in prep.). 
Based on the limited number of studies of actual explosion-induced ear trauma in fresh cadavers (Ketten, 2004), it was judged that a SEL $>190 \mathrm{~dB}$ re $1 \mu \mathrm{Pa}^{2} \mathrm{~s}$ would very likely result in permanent hearing loss. The model estimated an annual total of approximately 1,280 impact events in which animals were very likely to sustain permanent hearing loss (Table 2).

\section{Estimated effect distances - near surface}

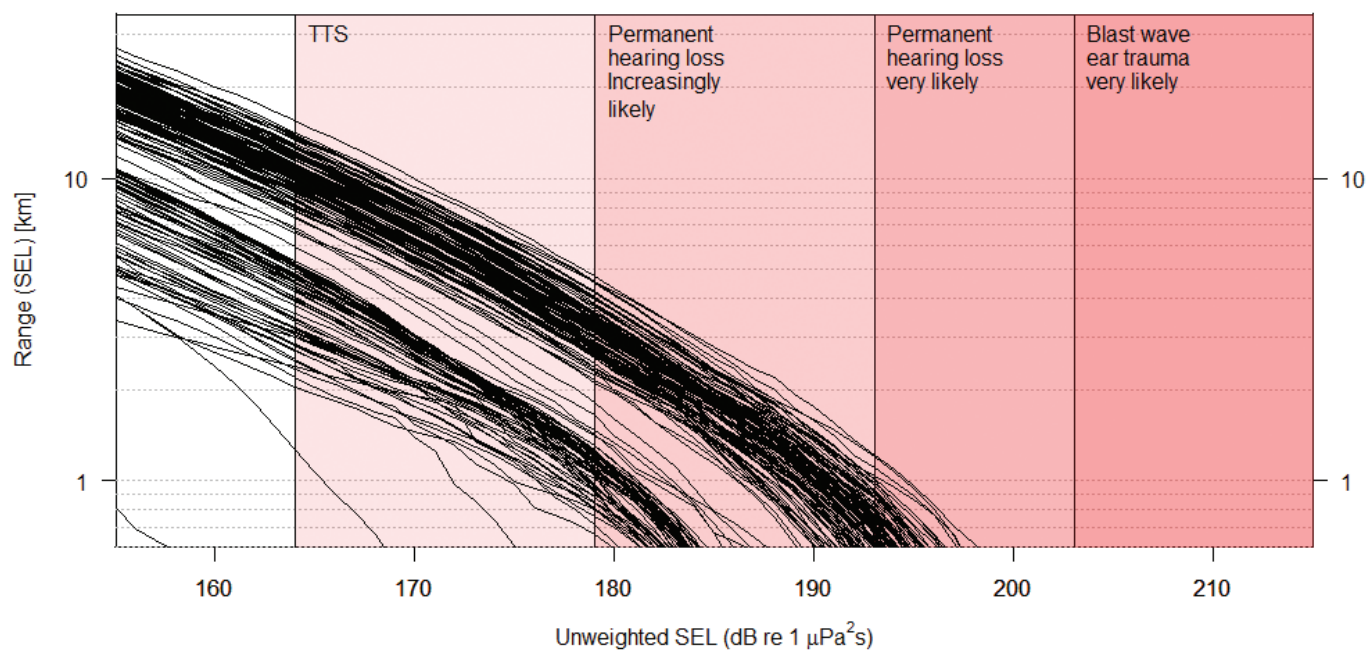

Estimated effect distances - near bottom

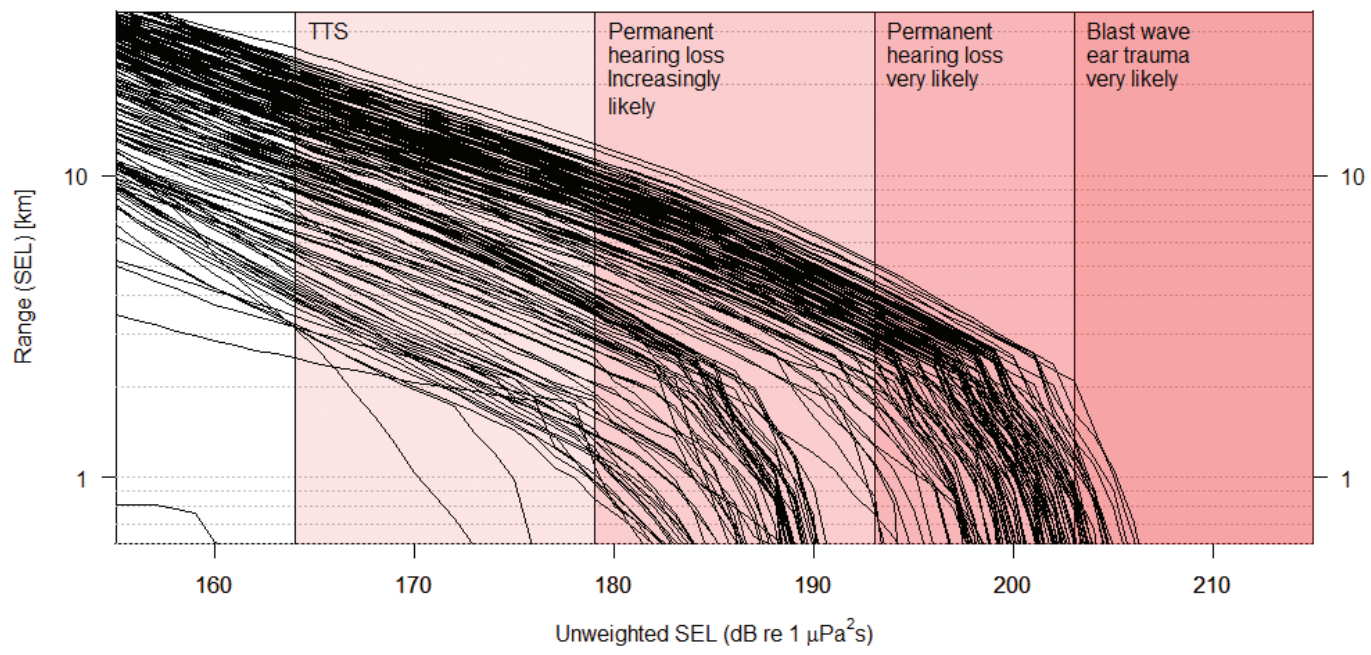

Figure 9. Modelled effect distances for a harbour porpoise at $1 \mathrm{~m}$ above the bottom (top) and $1 \mathrm{~m}$ below the surface (bottom) as a function of SEL threshold. Each black curve indicates a single explosion in the years 2010 and 2011. Vertical lines bordering the pink shaded areas represent the TTS, PTS, and ear trauma onset threshold values (see Table 1). 


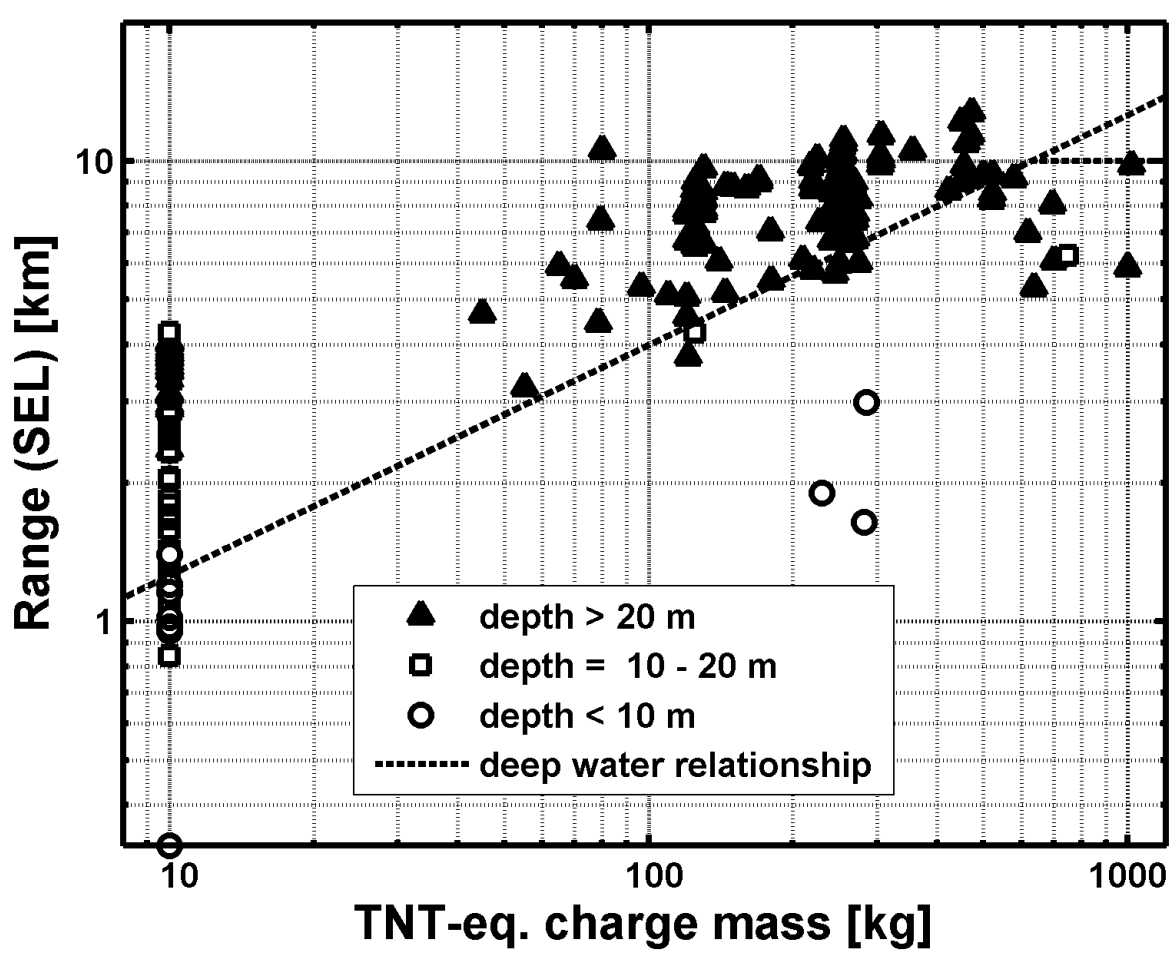

Figure 10. Modelled effect distances for a harbour porpoise at $1 \mathrm{~m}$ from the bottom as a function of charge mass for the lower limit for PTS (179 dB re $\left.1 \mu \mathrm{Pa}^{2} \mathrm{~s}\right)$. Symbols indicate different water depths at the location of explosion, showing lower effect distances for shallow water explosions. For comparison, the dashed line shows the deep-water prediction using the Weston (1960) model.

\section{Estimated auditory impact of detoniations}

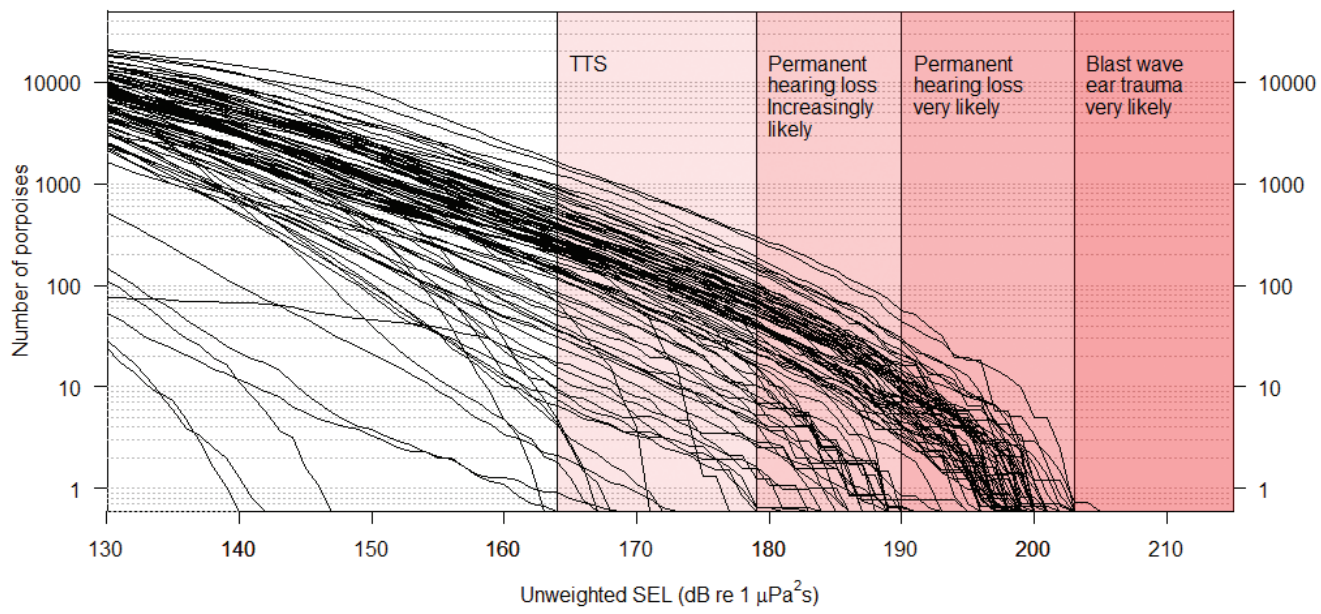

Figure 11. Estimated number of harbour porpoises affected by each explosion (black lines) as a function of received (unweighted) SEL for 88 explosions occurring in the DCS in the period between March 2010 and March 2011, assuming animals are $50 \%$ at the surface and 50\% near the bottom. Model SEL estimates were empirically corrected to match field acoustic measurements (see "Methods" section for details). Vertical lines bordering the pink shaded areas represent the TTS, PTS, and ear trauma onset threshold values (see Table 1). 
Table 2. The estimated average number of harbour porpoises impacted with a temporary or permanent hearing loss by a single explosive clearance and the total impact events (i.e., instances where a harbour porpoise was exposed to levels high enough to cause a specified effect) from the total of 88 explosions in the Dutch Continental Shelf (DCS) waters between March 2010 and March 2011. The effects considered were temporary and permanent hearing loss by explosions. Estimates are made for near the sea surface (i.e., at $1 \mathrm{~m}$ depth), near the bottom (i.e., $1 \mathrm{~m}$ above the bottom), and for the mean of these two, which assumed $50 \%$ of the harbour porpoises were near the surface and $50 \%$ were near the bottom.

\begin{tabular}{|c|c|c|c|c|c|c|c|}
\cline { 3 - 8 } \multicolumn{2}{c|}{} & \multicolumn{2}{c|}{$\begin{array}{c}\text { \# of harbour porpoises } \\
\text { (single explosion - average) }\end{array}$} & \multicolumn{3}{|c|}{$\begin{array}{c}\text { of impact events } \\
\text { (88 explosions) }\end{array}$} \\
\hline Type & $\begin{array}{c}\text { Threshold } \\
\text { unweighted } \\
\text { SEL } \\
\left.\text { (dB re 1 } \mu \mathrm{Pa}^{2} \mathrm{~s}\right)\end{array}$ & $\begin{array}{c}\text { If all } \\
\text { near } \\
\text { surface }\end{array}$ & $\begin{array}{c}\text { If all } \\
\text { near } \\
\text { bottom }\end{array}$ & $\begin{array}{c}\text { If 50\% near } \\
\text { surface and } \\
50 \% \text { near } \\
\text { bottom }\end{array}$ & $\begin{array}{c}\text { If all } \\
\text { near } \\
\text { surface }\end{array}$ & $\begin{array}{c}\text { If all } \\
\text { near } \\
\text { bottom }\end{array}$ & $\begin{array}{c}\text { If 50\% near } \\
\text { surface and } \\
50 \% \text { near } \\
\text { bottom }\end{array}$ \\
\hline $\begin{array}{c}\text { Blast wave } \\
\text { ear trauma } \\
\text { Very likely }\end{array}$ & 203 & 0 & 1 & 1 & 1 & 119 & 60 \\
\hline $\begin{array}{c}\text { Permanent } \\
\text { hearing loss } \\
\text { Very likely }\end{array}$ & 190 & 2 & 27 & 15 & 205 & 2,362 & 1,283 \\
\hline $\begin{array}{c}\text { Permanent } \\
\text { hearing loss } \\
\text { Increasingly } \\
\text { likely }\end{array}$ & 179 & 18 & 106 & 62 & 1,584 & 9,318 & 5,451 \\
\hline $\begin{array}{c}\text { TTS } \\
\text { Very likely }\end{array}$ & 164 & 190 & 448 & 319 & 16,721 & 39,413 & 28,067 \\
\hline
\end{tabular}

\section{Discussion}

Implication of Underwater Explosions for the North Sea Harbour Porpoise Population Risk of Permanent Hearing Loss-This study aimed to quantify the potential impact on harbour porpoises of underwater ordnance explosions on the Dutch Continental Shelf conducted by the RNLN. It was estimated that in a 1-y period (March 2010 to March 2011), the 88 explosions that occurred in the DCS very likely caused 1,280, and possibly up to 5,450 , permanent hearing loss events, with some animals potentially exposed multiple times.

The implication of a permanent hearing loss for a harbour porpoise depends on the severity of the hearing loss and the frequency range that is affected. Because of the configuration and mapping of frequencies in the inner ear, the impulse from a blast results in a broad movement of the inner ear membranes that is not frequency specific. Since high frequencies are encoded shortly after the entry to the cochlea, they are subject to impulse-related effects even though the peak in the spectrum of the signal is lower. Such effects were also observed in Kastelein et al. (2014a), who reported TTS to occur at increasingly higher frequencies with increasing noise exposure. When received levels of an explosion impulse exceed the threshold for causing a permanent hearing loss to part of the harbour porpoise's hearing range, a wider range of hearing is also likely to be negatively affected. Although the frequency range affected remains unknown, when explosion levels are high enough to cause primary blast injury resulting in ear trauma, exposures near those levels will very likely result in a large reduction in hearing ability over a broad frequency range.

While the dominant parts of the sound energy from the explosion shock wave is contained in low frequencies $(<1 \mathrm{kHz})$, harbour porpoises are known to echolocate at frequencies above $100 \mathrm{kHz}$ (Møhl \& Andersen, 1973). They do produce low-level sounds at frequencies below $1 \mathrm{kHz}$ that have been attributed to communication (Verboom \& Kastelein, 1997), while others argue that they communicate solely at frequencies $>100$ kHz (Hansen et al., 2008; Clausen et al., 
2010). Harbour porpoises rely on their echolocation ability on a daily basis to catch prey and navigate (Kastelein, 1997). Any impairment of their echolocation hearing abilities would likely lead to significant negative effects on their fitness. The implications of TTS are less clear. The estimated number of impact events for TTS by the model suggested that a large number of animals could have been exposed to one instance of TTS, and some could have experienced multiple exposures each year (see Aarts et al., in prep.). In principle, TTS is expected to recover quickly (within hours to days). Minor TTS in a low-frequency range outside the frequency regimes used for communication and echolocation are unlikely to significantly affect the animal's fitness. Repeated or severe TTS might result in noticeable, even if transitory, damage to the inner ear at the submicroscopic level (Kujiwa \& Liberman, 2009), which could have significant consequences for fitness and survival. It is unknown whether harbour porpoises would have responses similar to the species tested in Kujiwa \& Liberman.

The detonation activities in the DCS strongly peaked in March when the harbour porpoise abundance also peaks (Geelhoed et al., 2012). The percentage of animals estimated to have suffered from permanent hearing loss per year due to exposure to underwater explosions in the DCS could be at least $1.3 \%$ and potentially up to $8.7 \%$ of the harbour porpoise population present in the DCS (based on the average population size in the DCS of the four survey estimates in Geelhoed et al., 2012).

\section{Uncertainty in Estimated Impacts}

The predicted impacts contained uncertainties, which were attributed to the following factors: (1) difficulty of predicting the generation and propagation of underwater shock waves in shallow water at large distances, (2) lack of data on sensitivity of harbour porpoises exposed to explosion shock waves and broadband impulsive sound, and (3) a lack of knowledge on habitat use and movement patterns of harbour porpoises in the North Sea. The main uncertainties in the model predictions are discussed in the following sections. Uncertainties in habitat use are discussed in Aarts et al. (in prep.).

Sound Exposure Levels of Explosions in Shallow Water-The impact assessment relied on the validity of the propagation model used to estimate SEL for different explosive charge mass and water depths. With the adopted deep water model for the explosion source energy level from Weston (1960), prior to correction, the model systematically overestimated the observed broadband SEL (by approximately $8 \mathrm{~dB}$ ), particularly at frequencies higher than $200 \mathrm{~Hz}$.
Different mechanisms could be responsible for the overestimation of the (uncorrected) model. For example, interaction with the sea floor for an explosive detonated near or on the bottom, energy losses due to a blow-out as the shock wave first reaches the surface, energy loss by cavitation close to the surface, a lower effective charge mass due to degradation of the explosive charge, or propagation losses due to multiple interactions with wind-generated bubbles at larger distances could all lead to reductions in the estimated resulting SEL (Cole, 1965; Ainslie, 2010; Pfeiffer, 2014).

The explosion source model assumed that no blow-out at the surface occurred. Surface blow-out may lead to pressure release in the bubble, leading to lowered (horizontal) radiation efficiency. This may occur for large explosives in very shallow areas; however, the effect on the radiated energy in the shock wave at large horizontal distances is not well understood (Weston, 1960). No surface blow-out occured during the measured explosions, which were both typical in charge mass and water depth (see Figure 4). The UXO were also assumed to detonate at full power, and possible degradation that may have occurred due to long contact with sea water (Pfeiffer, 2014) was not taken into consideration. Degradation occurs more strongly for some types of UXO (especially thin-walled mines or aluminium torpedoes), but other types of ammunition show less signs of strong deterioration (Pfeiffer, 2014). Since most of the larger UXO found at sea by the RNLN are aerial bombs, the assumption of full power detonation is likely a reasonable assumption for the majority of the UXO considered herein (von Benda-Beckmann et al., 2015).

To adjust for the overprediction in SEL, the acoustic source model was corrected to match measured SEL levels at various depths. Because these experiments were representative of typical charges and water depths at which these detonations occur, the corrected model predictions were expected to give a realistic estimate of the impact distances for most of the explosions modelled.

Also, for very small charges $(\sim 1-\mathrm{kg}$ TNT eq. charge mass), the uncorrected source model systematically overestimated broadband SEL measurements by Soloway \& Dahl (2014) by $\sim 7.6 \mathrm{~dB}$ $(\mathrm{SD}=2.1 \mathrm{~dB})$ at distances up to $1 \mathrm{~km}$. This overestimate also occurred for explosions in midwater, and these explosives were calibrated charges. As a result, uncertainty in charge mass and effect of bottom interactions of a bottom explosion were unlikely causes for the model overestimating the SEL of an explosion. After applying the empirical correction factor proposed in this study, a better match was obtained for the Soloway \& Dahl (2014) measurements. The corrected model 
slightly underestimated the Soloway \& Dahl (2014) measurements by $1.5 \mathrm{~dB}(\mathrm{SD}=2.3 \mathrm{~dB})$ (1-sigma STD).

A plausible cause for the overestimation using the uncorrected model was the effect of the cavitation zone on the propagation of the generated shock wave. The cavitation zone created by the shock wave was likely to lead to energy loss and also could act as a bubble screen for the bottomreflected paths, including the shock wave. In deep water, shielding by the cavitation zone is unlikely to have such a noticeable effect on the measured SEL because a large fraction of the bottom reflections would have travelled beyond the cavitation zone or would arrive much later than the direct blast. The size of the cavitation zone would be a function of the charge mass and depth of the explosion. The slight overestimation observed when comparing the model to the Soloway \& Dahl (2014) datasets agreed with this interpretation as a smaller charge mass would result in a smaller cavitation zone and, hence, less absorption.

Another effect that becomes important at large distances is the attenuation by wind-generated bubbles. This is most noticeable at higher frequencies and longer distances. Attenuation by wind-generated bubbles could in part explain the large discrepancy between the modeled estimate and the measurements at frequencies above $10 \mathrm{kHz}$. Alternatively, this discrepancy could be caused by the low-pass filter on the measurement devices. However, since the energy above $10 \mathrm{kHz}$ did not contribute significantly to the broad-band energy at a distance of $2 \mathrm{~km}$, its impact on harbour porpoises could be ignored.

It is concluded, therefore, that the corrected model provided a reasonable estimate of the SEL within the first $2 \mathrm{~km}$ around the explosion. This corresponded to the lower limit for effect distances for smaller charges $(<25 \mathrm{~kg})$. For larger explosions $(>25 \mathrm{~kg})$, for which the effect distances for the lower limit of PTS onset (SEL $>179 \mathrm{~dB}$ re $1 \mu \mathrm{Pa}^{2} \mathrm{~s}$ ) approached the 10 to $20 \mathrm{~km}$, the model requires further validation.

Uncertainties in Dose-Response Relationships for Hearing Loss-As there are no measurements of onset thresholds of permanent hearing loss in any marine mammal species, we considered a range of SEL thresholds at which permanent hearing loss could occur. A lower limit threshold above which permanent hearing loss was considered increasingly likely to occur was obtained by following the approach proposed by Southall et al. (2007). That study assumed that PTS occurs at a level of $15 \mathrm{~dB}$ above the TTS onset. Data from Kastelein et al. (2012b) suggest there could be a higher TTS/PTS exposure difference. Kastelein et al. (2014a) demonstrated a positive correlation between frequency and rate of TTS increase. This would result in a wider offset between TTS and PTS than assumed in the present study and, consequently, a higher PTS threshold, especially for the low-frequency range containing most of the propagated energy from an explosion. Therefore this SEL threshold of $179 \mathrm{~dB}$ re $1 \mu \mathrm{Pa}^{2} \mathrm{~s}$ might be conservative and may lead to an overestimation of the number of animals that could be affected by permanent hearing loss.

In this study, the effect of frequency weighting of the SEL was neglected when estimating the risk of TTS and PTS on the basis that our risk criterion was based on observation of TTS onset due to a single airgun exposure (Lucke et al., 2009), which was more representative of the explosion sound than other stimuli for which TTS measurements have been obtained in harbour porpoises.

Weighting of the received SEL would need to be compared to the corresponding weighted exposure levels at which TTS was measured by Lucke et al. (2009). Since the very low frequencies propagate poorly in shallow waters, the frequency content was similar to that of an airgun, and, hence, the frequency weighting was unlikely to affect the results as the risk threshold for TTS will be lowered by the same order as the predicted weighted SEL. Therefore, it was expected that the lack of frequency weighting does not affect the estimated impact of temporary and permanent hearing loss.

Values of peak overpressure levels at which ear trauma was observed in eight cadaveric harbour porpoises exposed to underwater explosions (Ketten, 2004) were used to put an upper limit to the PTS SEL threshold. Ketten (2004) noted that other characteristics of the shock wave are likely to be important in determining the risk of injury and need to be considered such as near field vs far field loading effects; exponential vs sinusoidal bursts; and synergistic effects of rate of pressure increase, peak sound pressure, waveform, duration, and rise time, coupled with body mass (species with smaller average body mass have greater liability for shock-induced trauma, particularly in air-filled tissues and from bubble formation and oscillation, lesser body shadow protection, etc.). It is not obvious how to translate the experimental conditions employed by Ketten to large explosions at sea and with greater distances from the sourceexcept in terms of received peak sound pressures. That is equivocal as well, however, because of the complex physics of propagating shock waves. Further, it is important to note that tissue and whole system responses are different in live vs postmortem specimens. Even in the freshest material, the mechanical properties for some or all tissues may be altered due to death. In some cases, postmortem material may be more responsive 
than living tissue; in others, less. Thus, cadaveric results are not definitive for live cases. They do provide insights into purely mechanical responses that may occur in marine mammals due to shock waves, however. For this reason, the Ketten study focused on the tissue changes that are essentially mechanical and should be robust even in cadavers such as ossicular fracture; middle, fenestral, and inner ear membrane responses; and the minimal end and massive, distinct trauma in other tissues such as the liver and brain.

\section{Conclusion}

In this study, the impact of explosive clearance activities of historical UXO on harbour porpoises in the southern North Sea was assessed. This is the first study to address on a broad scale the potential impacts of underwater explosions on any marine mammal species. This assessment was based on actual explosion events carried out by the RNLN in 2010 and 2011, using information on explosive type, location, and timing of the detonations as made available by the Netherlands Ministry of Defense (NLMoD). For these explosion events, impact areas were modelled and compared to the aerial survey-based estimates of harbour porpoise distribution during the same period. While the data used in the analysis were site specific, the methodology used in this study is broadly applicable to other areas in which underwater explosions occur.

Within the period of 2010 and 2011, a total of 210 explosions occurred, with charge masses ranging from several to one thousand kilograms TNT eq. The model estimated that the 88 explosions that occured in the DCS between March 2010 and March 2011 (the period of overlap between aerial surveys and reported explosion events) were very likely to have caused 1,280 , and possibly up to 5,450 , permanent hearing loss events (i.e., instances of a harbour porpoise predicted to have received sufficient sound exposure to cause permanent hearing loss). Distances to which there was a risk of permanent hearing loss were on the order of one to several kilometres, and possibly further for larger explosions.

The predicted impacts in this study contain uncertainties, which were attributed to the following factors:

- Lack of data on sensitivity of harbour porpoises to explosion shock waves and broadband impulsive sound
- Difficulty in predicting the generation and propagation of underwater shock waves in shallow water at large distance

- Lack of knowledge on movement patterns and habitat use of harbour porpoises

This study confirms earlier concerns (Nützel, 2008; Ainslie et al., 2009; Camphuysen \& Siemensma, 2011: Koschinski, 2012) that explosions in the North Sea pose a risk to harbour porpoises and has prompted the NLMoD to investigate and implement mitigation measures to reduce the adverse effects of underwater explosions. Even the most optimistic estimates presented in this study suggested that there was a significant risk that hundreds of individual harbour porpoises were negatively affected by the explosions, although the population-level consequences could not be judged. Models are being developed to assess population-level consequences of underwater sound on harbour porpoises (Lusseau et al., 2012; Harwood et al., 2013; Nabe-Nielsen et al., 2014). The detonation activities by all nations active in the North Sea, as well as information on distribution of harbour porpoises, should be considered in order to judge the cumulative effect of all explosions on the harbour porpoise population in the North Sea. To enable such assessment, it is recommended that reportings of detonations contain the necessary information (e.g., location, depth, time, and estimated charge mass) to enable an impact assessment.

\section{Acknowledgments}

We acknowledge the valuable discussions with Lieutenant Commander Jurriën van Kasteren and Lieutenant Commander Menno van der Eerden on the practices and procedures of underwater explosive clearance activities by the RNLN and Defence Explosive Ordnance Disposal Service (DEODS). We further thank the Netherlands Ministry of Defence and the KNMI for making available the reported explosion events used in this study, and Lieutenant Commander René Dekeling and Christ de Jong for a valuable discussion on the risk assessment. This work greatly benefited from discussions with Rolf van Wees, Hans van Aanhold, and Mark Tyler Street on the physics and the measurement and modelling of underwater explosions in shallow water environments. Further, we thank Reinoud van de Kasteele and Stefania Giodini for helping in the analysis of the 2010 explosion measurements. Finally, we thank the two anonymous reviewers for their useful comments and suggestions, which helped to improve 
the quality of the manuscript. Özkan Sertlek and Geert Aarts have been funded by NWO-ZKO grant "Effects of Underwater Noise on Fish and Marine Mammals in the North Sea." D. R. Ketten was supported by the Living Marine Resources and ONR programmes of the U.S. Navy to study underwater blast trauma and noise impacts, and by the Hanse-Wissenschaftskolleg.

\section{Literature Cited}

Aarts, G., von Benda-Beckmann, A. M., Lucke, K., Sertlek, H. O., van Bemmelen, R., Geelhoed, S. C. V., ... Kirkwood, R. (In prep.). Movement behaviour influences population level exposure to underwater sound: Impact of explosions on harbour porpoises.

Ainslie, M. A. (2010). Principles of sonar performance modeling. Chichester, UK: Springer-Praxis. http://dx. doi.org/10.1007/978-3-540-87662-5

Ainslie, M. A., de Jong, C. A. F., Dol, H. S., Blacquière, G., \& Marasini, C. (2009). Assessment of natural and anthropogenic sound sources and acoustic propagation in the North Sea (TNO Report TNO-DV 2009 C085). The Hague: TNO.

Akamatsu, T., Matsuda, A., Suzuki, S., Wang, D., Wang, K., Suzuki, M., . . Oota, K. (2005). New stereo acoustic data logger for free-ranging dolphins and porpoises. Marine Technology Society Journal, 38, 6-12. http://dx. doi.org/10.4031/002533205787443980

Camphuysen, C. J. (2011). Recent trends and spatial patterns in near-shore sightings of harbour porpoises (Phocoena phocoena) in the Netherlands (Southern Bight, North Sea), 1990-2010. Lutra, 54, 39-47.

Camphuysen, C. J., \& Siemensma, M. L. (2011). Conservation plan for the harbour porpoise Phocoena phocoena in The Netherlands: Towards a favourable conservation status (NIOZ Report 2011-07). Texel: Royal Netherlands Institute for Sea Research.

Chapman, N. R. (1985). Measurement of the waveform parameters of shallow explosive charges. The Journal of the Acoustical Society of America, 78, 672-681. http:// dx.doi.org/10.1121/1.392436

Clausen, K. T., Wahlberg, M., Beedholm, K., DeRuiter, S., \& Madsen, P. T. (2010). Click communication in harbour porpoises Phocoena phocoena. The International Journal of Animal Sound and Its Recording, 20, 1-28. http://dx.doi.org/10.1080/09524622.2011.9753630

Cole, R. H. (1965). Underwater explosions. [Originally published in 1948 by Princeton University Press, Dover, NY].

Culik, B., Koschinski, S., Tregenza, N., \& Ellis, G. M. (2001). Reactions of harbor porpoises Phocoena phocoena and herring Clupea harengus to acoustic alarms. Marine Ecology Progress Series, 211, 255-260. http:// dx.doi.org/10.3354/meps 211255

Danil, K., \& St. Leger, J. A. (2011). Seabird and dolphin mortality associated with underwater detonation exercises. Marine Technology Society Journal, 6, 89-95. http://dx.doi.org/10.4031/MTSJ.45.6.5

Finneran, J. J., \& Jenkins, A. K. (2012). Criteria and thresholds for U.S. Navy acoustic and 51 explosive effects analysis. San Diego: SPAWAR Systems Center Pacific. 64 pp.

Finneran, J. J., \& Schlundt, C. E. (2013). Effects of fatiguing tone frequency on temporary threshold shift in bottlenose dolphins (Tursiops truncatus). The Journal of the Acoustical Society of America, 133(3), 1819-1826. http://dx.doi.org/10.1121/1.3641449

Fletcher, H., \& Munson, W. A. (1933). Loudness, its definition, measurement and calculation. The Journal of the Acoustical Society of America, 5, 82-108. http://dx.doi. org/10.1121/1.1915637

Geelhoed, S., Scheidat, M., Aarts, G., van Bemmelen, R., Janinhoff, N., Verdaat, H., \& Witte, R. R. H. (2012). Shortlist masterplan wind aerial surveys of harbour porpoises on the Dutch Continental Shelf (IMARES Report Number C103/11). Texel: Den Burg.

Gilles, A., Scheidat, M., \& Siebert, U. (2009). Seasonal distribution of harbour porpoises and possible interference of offshore wind farms in the German North Sea. Marine Ecology Progress Series, 383, 295-307. http:// dx.doi.org/10.3354/meps08020

Hansen, M., Wahlberg, M., \& Madsen, P. T. (2008). Low-frequency components in harbour porpoise (Phocoena phocoena) clicks: Communication signal, by-product, or artifacts? The Journal of the Acoustical Society of America, 124, 4059-4068. http://dx.doi.org/ $10.1121 / 1.2945154$

Harwood, J., King, S., Schick, R., Donovan C., \& Booth, C. (2013). A protocol for implementing the interim population consequences of disturbance (PCOD) approach: Quantifying and assessing the effects of UK offshore renewable energy developments on marine mammal populations (Report SMRUL-TCE-2013-014; Scottish Marine and Freshwater Science, 5[2]).

Hiby, L., \& Lovell, P. (1998). Using aircraft in tandem formation to estimate abundance of harbour porpoise. Biometrics, 54, 1280-1289. http://dx.doi.org/10. 2307/2533658

Kastelein, R. A. (1997). Food consumption and growth of marine mammals (Ph.D. thesis). Landbouwuniversiteit Wageningen, The Netherlands. 647 pp.

Kastelein, R. A., Gransier, R., Hoek, L., \& de Jong, C. A. F. (2012a). The hearing threshold of a harbor porpoise (Phocoena phocoena) for impulsive sounds (L). The Journal of the Acoustical Society of America, 132(2), 607-610. http://dx.doi.org/10.1121/1.4733552

Kastelein, R. A., Gransier, R., Hoek, L., \& Olthuis, J. (2012b). Temporary threshold shifts and recovery in a harbor porpoise (Phocoena phocoena) after octave-band noise at $4 \mathrm{kHz}$. The Journal of the Acoustical Society of America, 132, 3525. http://dx.doi. org/10.1121/1.4757641

Kastelein, R. A., Gransier, R., Hoek, L., \& Rambags, M. (2013). Hearing frequency thresholds of a harbour 
porpoise (Phocoena phocoena) temporarily affected by a continuous $1.5 \mathrm{kHz}$ tone. The Journal of the Acoustical Society of America, 134, 2286-2292. http://dx.doi.org/ $10.1121 / 1.4816405$

Kastelein, R. A., Gransier, R., Marijt, M. A. T., \& Hoek, L. (2015a). Hearing frequencies of a harbor porpoise (Phocoena phocoena) temporarily affected by played back offshore pile-driving sounds. The Journal of the Acoustical Society of America, 137, 556. http://dx.doi. org/10.1121/1.4906261

Kastelein, R. A., Gransier, R., Schop, J., \& Hoek, L. (2015b). Effects of exposure to intermittent and continuous 6-7 kHz sonar sweeps on harbor porpoise (Phocoena phocoena) hearing. The Journal of the Acoustical Society of America, 137(4), 1623-1633. http://dx.doi. org/10.1121/1.4916590

Kastelein, R. A., Gransier, R., Schop, J., \& Hoek, L. (2014a). Frequency of greatest temporary hearing threshold shift in harbor porpoises (Phocoena phocoena) depends on the noise level. The Journal of the Acoustical Society of America, 136, 1410-1418. http:// dx.doi.org/10.1121/1.4892794

Kastelein, R. A., Bunskoek, P., Hagedoorn, M., Au, W. W. L., \& de Haan, D. (2002). Audiogram of a harbor porpoise (Phocoena phocoena) measured with narrowband frequency-modulated signals. The Journal of the Acoustical Society of America, 112, 334-344. http:// dx.doi.org/10.1121/1.1480835

Kastelein, R. A., Hoek, L., Gransier, R., Rambags, M., \& Claeys, N. (2014b). Effect of level, duration, and interpulse interval of 1-2 kHz sonar signal exposures on harbour porpoise hearing. The Journal of the Acoustical Society of America, 136, 412-422. http://dx.doi.org/10. $1121 / 1.4883596$

Ketten, D. R. (2004). Experimental measures of blast and acoustic trauma in marine mammals (ONR Final Report N000149711030).

Ketten, D. R. (2012). Marine mammal auditory system noise impacts: Evidence and incidence. In A. N. Popper $\&$ A. Hawkins (Eds.), The effects of noise on aquatic life (pp. 207-212). New York: Springer. http://dx.doi. org/10.1007/978-1-4419-7311-5_46

Ketten, D. R., Lien, J., \& Todd, S. (1993). Blast injury in humpback whale ears: Evidence and implications. The Journal of the Acoustical Society of America, 94(3/2), 1849-1850. http://dx.doi.org/10.1121/1.407688

Koschinski, S. (2012). Underwater noise pollution from munitions clearance and disposal, possible effects on marine vertebrates, and its mitigation. Marine Technology Society Journal, 45, 80-88. http://dx.doi. org/10.4031/MTSJ.45.6.2

Kryter, K. D. (1994). The handbook of hearing and the effects of noise. New York: Academic Press. 673 pp.

Kryter, K. D., Ward, W. D., Miller, J. D., \& Eldredge, D. H. (1966). Hazardous exposure to intermittent and steady state noise. The Journal of the Acoustical Society of America, 39, 451-464. http://dx.doi.org/10. $1121 / 1.1909912$
Kujiwa, S. G., \& Liberman, M. C. (2009). Adding insult to injury: Cochlear nerve degeneration after "temporary" noise-induced hearing loss. Journal of Neuroscience, 20, 14077-14085. http://dx.doi.org/10.1523/JNEUROSCI. 2845-09.2009

Lewis, J. A. (1996). Effects of underwater explosions on life in the sea. Melbourne, Victoria: Department of Defence, Defence Science and Technology Organisation. 38 pp.

Lucke, K., Siebert, U., Lepper, P. A., \& Blanchet, M-A. (2009). Temporary shift in masked hearing thresholds in a harbor porpoise (Phocoena phocoena) after exposure to seismic airgun stimuli. The Journal of the Acoustical Society of America, 125(6), 4060-4070. http://dx.doi. org/10.1121/1.3117443

Lusseau, D., Christiansen, F., Harwood, J., Mendes, S., Thompson, P. M., Smith, K., \& Hastie, G. D. (2012). Assessing the risks to marine mammal populations from renewable energy devices - An interim approach (Final Workshop Report). 29 pp.

Madsen,P.A. (2005). Marine mammals and noise: Problems with root mean square sound pressure levels for transients. The Journal of the Acoustical Society of America, 117(6), 3952-3957. http://dx.doi.org/10.1121/1.1921508

Møhl, B., \& Andersen, S. (1973). Echolocation: Highfrequency component in click of harbor porpoise (Phocoena ph. L.). The Journal of the Acoustical Society of America, 54, 1368-1372. http://dx.doi.org/10. 1121/1.1914435

Nabe-Nielsen, J., Sibly, R. M., Tougaard, J., Teilmann, J., \& Sveegaard, S. (2014). Effects of noise and by-catch on a Danish harbour porpoise population. Ecological Modelling, 272, 242-251. http://dx.doi.org/10.1016/j. ecolmodel.2013.09.025

National Research Council. (2003). Ocean noise and marine mammals. Washington, DC: The National Academies Press.

Nützel, B. (2008). Untersuchungen zum schutz von schweinswalen vor schockwellen [Investigations for the protection of harbour porpoises to blast waves] (Forschungsanstalt der Bundeswehr für Wasserschall und Geophysik [FWG], Technischer Bericht TB 20087).

OSPAR Commission. (2010). Quality status report: Assessment of the impact of dumped conventional and chemical munitions. London: OSPAR Commission.

Pfeiffer, F. (2014). Changes in properties of explosives due to prolonged seawater exposure. Marine Technology Society Journal, 102-110. http://dx.doi.org/10.4031/MT SJ.46.1.5

Richardson, W. J., Greene, C. R., Jr., Malme, C. I., \& Thomson, D. H. (1995). Marine mammals and noise. San Diego: Academic Press. 576 pp.

Rue, H., Martino, S., \& Chopin, N. (2009). Approximate Bayesian inference for latent Gaussian models by using integrated nested Laplace approximations. Journal of the Royal Statistical Society: Series B (Statistical Methodology), 71, 319-392. http://dx.doi.org/10.1111/ j.1467-9868.2008.00700.x 
Scheidat, M., Gilles, A., \& Siebert, U. (2005). Applying the circle-back method to estimate $g(0)$-Experiences and results from aerial surveys in German waters. Proceedings of the "Workshop on Estimation of $\mathrm{g}(0)$ in Line Transect Surveys of Cetaceans" held at the European Cetacean Society's 18th Annual Conference, Kolmården Djur Park, Kolmården, Sweden.

Scheidat, M., Verdaat, H., \& Aarts, G. ( 2012). Using aerial surveys to estimate density and distribution of harbour porpoises in Dutch waters. Journal of Sea Research, 69, 1-7. http://dx.doi.org/10.1016/j.seares.2011.12.004

Scheidat, M., Gilles, A., Kock, K. H., \& Siebert, U. (2008). Harbour porpoise Phocoena phocoena abundance in the southwestern Baltic Sea. Endangered Species Research, 5, 215-223. http://dx.doi.org/10.3354/esr00161

Schuknecht, H. F. (1993). Pathology of the ear (2nd ed.). Philadelphia: Lea-Felbiger. http://dx.doi.org/10.1002/ hed.2880160317

Sertlek, H. Ö., \& Ainslie, M. A. (2014). A depth-dependent formula for shallow water propagation. The Journal of the Acoustical Society of America, 136(2), 573-582. http://dx.doi.org/10.1121/1.4884762

Sertlek, H. Ö., Ainslie, M. A., \& Heaney, K. D. (In prep.). Range-dependent propagation equations and results for Pekeris waveguide. The Journal of the Acoustical Society of America.

Soloway, A. G., \& Dahl, P. H. (2014). Peak sound pressure and sound exposure level from underwater explosions in shallow water. The Journal of the Acoustical Society of America, 136(3), EL219-EL223. http://dx.doi.org/ $10.1121 / 1.4892668$

Southall, B. L., Bowles, A. E., Ellison, W. T., Finneran, J. J., Gentry, R. L., Greene, C. R., Jr., . . . Tyack, P. L. (2007). Marine mammal noise exposure criteria: Initial scientific recommendations. Aquatic Mammals, 33(4), 411-521. http://dx.doi.org/10.1578/AM.33.4.2007.411

Suzuki, Y., \& Takeshima, H. (2004). Equal loudness-level contours for pure tones. The Journal of the Acoustical Society of America, 116, 918-933. http://dx.doi.org/ $10.1121 / 1.1763601$

Tougaard, J., Wright, A. J., \& Madsen, P. T. (2015). Cetacean noise criteria revisited in the light of proposed exposure limits for harbour porpoises. Marine Pollution Bulletin, 90(1-2), 196-208. http://dx.doi.org/10.1016/j. marpolbul.2014.10.051

Tougaard, J., Carstensen, J., Teilmann, J., Skov, H., \& Rasmussen, P. (2009). Pile-driving zone of responsiveness extends beyond $20 \mathrm{~km}$ for harbour porpoises (Phocoena phocoena [L.]). The Journal of the Acoustical Society of America, 126(1), 11-14. http://dx. doi.org/10.1121/1.3132523

Tyack, P. L. (2008). Implications for marine mammals of large-scale changes in the marine acoustic environment. Journal of Mammalogy, 89(3), 549-558. http://dx.doi. org/10.1644/07-MAMM-S-307R.1

Verboom, W. C., \& Kastelein, R. A. (1997). Structure of harbour porpoise (Phocoena phocoena) click train signals. In A. J. Read, P. R. Wiepkema, \& P. E. Nachtigall (Eds.), The biology of the harbour porpoise (pp. 343362). Woerden, The Netherlands: De Spil Publishers.

Verboom, W. C., \& Kastelein, R. A. (2005). Some examples of marine mammal "discomfort thresholds" in relation to man-made noise. Proceedings of UDT Europe 2005, Amsterdam.

von Benda-Beckmann, A. M., Aarts, G., Lucke, K., Verboom, W. C., Kastelein, R. A., Sertlek, O., . . . Ainslie, M. A. (2015). Assessment of impact of underwater clearance of historical explosives by the Royal Netherlands Navy on harbour porpoises in the North Sea (TNO Technical Report TNO 2014 R10916).

Wensveen, P. J., Huijser, L. E. A., Hoek, L., \& Kastelein, R. A. (2014). Equal latency contours and auditory weighting functions for the harbour porpoise (Phocoena phocoena). The Journal of Experimental Biology, 217, 359-369. http://dx.doi.org/10.1242/jeb.091983

Westgate, A. J., Read, A. J., Berggren, P., Koopman, H. N., \& Gaskin, D. E. (1995). Diving behaviour of harbour porpoises, Phocoena phocoena. Canadian Journal of Fisheries and Aquatic Science, 52, 1065-1073. http:// dx.doi.org/10.1139/f95-104

Weston, D. E. (1960). Underwater explosions as acoustic sources. Proceedings of the Physical Society, 76, 233 249. http://dx.doi.org/10.1088/0370-1328/76/2/307

Weston, D. E. (1962). Explosive sources in underwater acoustics. New York: Plenum Press. 


\section{Appendix A}

To delimit the effect range at which permanent hearing loss becomes "very likely," levels at which ear trauma occurred in fresh animal cadavers resulting from primary blast injury were considered. Peak overpressure was used in Ketten (2004) to predict the occurrence of primary blast injury. Here, instead, the peak overpressure was empirically related to SEL for measured explosion sound in shallow water due to the difficulties of modelling peak overpressure in shallow water. Then, an effective SEL that corresponded to peak overpressures resulting in ear trauma was estimated.

To indicate at what distances a risk of blast injury occurred, the measured peak overpressure was related to measured SEL using the data from the monitored explosions (Figure A1). Measured peak overpressure and broadband SEL showed a roughly log-linear relationship with a greater scatter for measurements close to the surface (depths smaller than $6 \mathrm{~m}$ ).

Observations by Ketten (2004) showed that ear trauma occurred at peak overpressures exceeding $172 \mathrm{kPa}(25 \mathrm{psi})$, indicated by the grey dashed line in Figure A1, which corresponded to a range in SEL of 195 to $203 \mathrm{~dB}$ re $1 \mu \mathrm{Pa}^{2}$ s, which suggests that ear trauma is very likely to occur at SEL $>203 \mathrm{~dB}$ re $1 \mu \mathrm{Pa}^{2} \mathrm{~s}$. No ear trauma could be observed for peak overpressures of $69 \mathrm{kPa}(10 \mathrm{psi})$ as indicated by the grey solid line, suggesting that ear trauma due to primary blast injury is unlikely to occur at SEL $<190 \mathrm{~dB}$ re $1 \mu \mathrm{Pa}^{2} \mathrm{~s}$. The probability of ear trauma to occur between $\mathrm{SEL}=190$ and $203 \mathrm{~dB}$ re $1 \mu \mathrm{Pa}^{2} \mathrm{~s}$ was considered to be increasingly likely.

It is expected that the acoustics of a blast event at a received level of SEL $>190 \mathrm{~dB}$ re $1 \mu \mathrm{Pa}^{2} \mathrm{~s}$ is very likely (> 95\% probability) to cause PTS. The delimitation between the terms "unlikely" (less than 5\% probability), "increasingly likely" (probability between 5 and 95\%), and "very likely" (greater than 95\%) adopted in this study are not based on a statistical evaluation of the data; rather, they should be considered as indicative of the consensus opinion of the authors of the likelihood at which these effects occur.

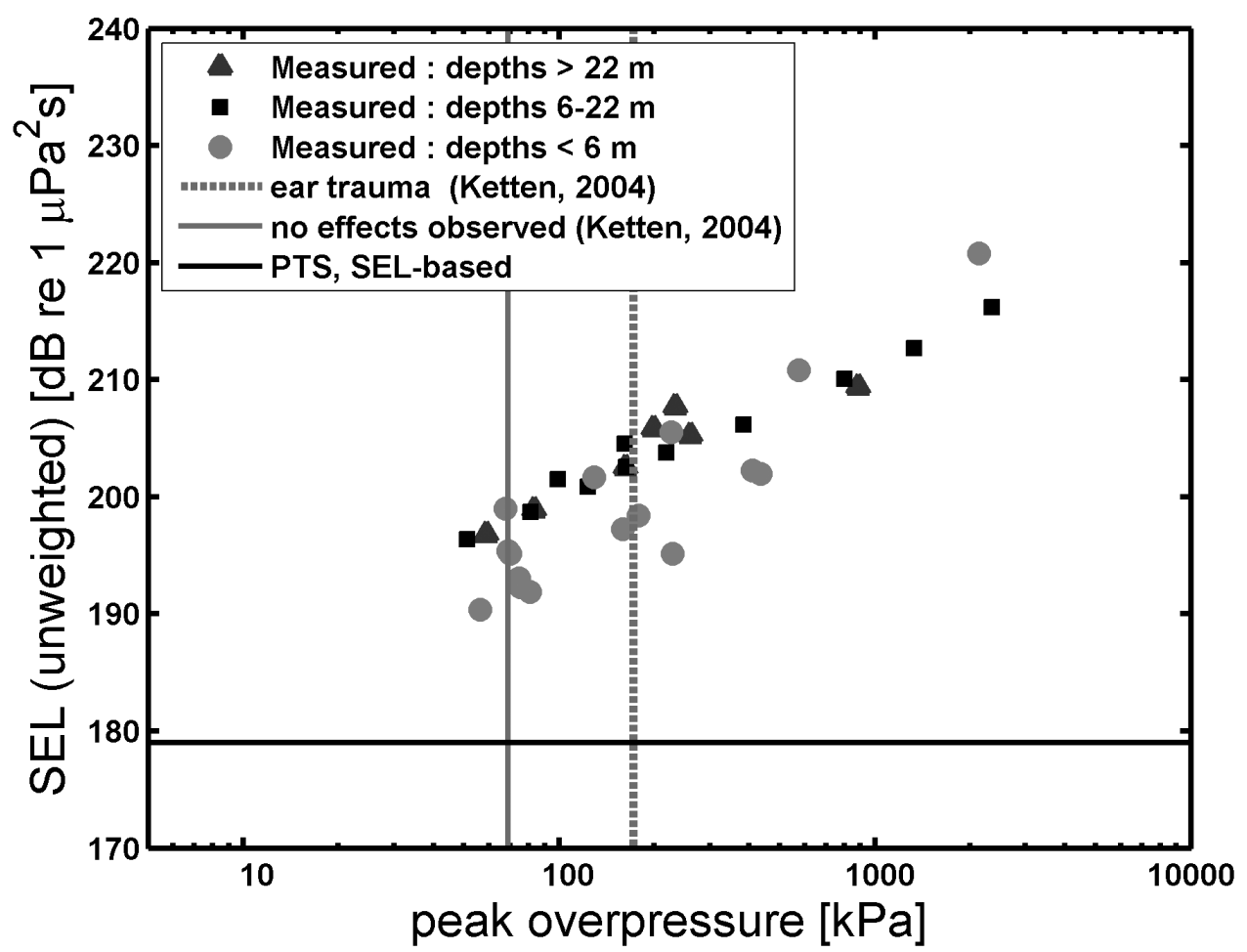

Figure A1. Empirical relation between unweighted broadband SEL and peak overpressure for shallow water explosions of 263-kg TNT eq. charge mass, both measured at different distances (see "Results" for more details). Superimposed are risk thresholds for a lower limit for PTS onset (black line, based on the Lucke et al. [2009] TTS measurement and adding $15 \mathrm{~dB}$ following Southall et al. [2007]) and observed pathological effects (grey lines, observed by Ketten [2004]). 